OPEN ACCESS

Edited by:

Wallace B. Thoreson, University of Nebraska Medical

Center, United States

Reviewed by: Jozsef Vigh,

Colorado State University, United States

Robert Gabriel,

University of Pécs, Hungary

${ }^{*}$ Correspondence:

Evanna L. Gleason

egleaso@/su.edu

Specialty section:

This article was submitted to

Cellular Neurophysiology,

a section of the journal

Frontiers in Cellular Neuroscience

Received: 17 June 2021

Accepted: 19 July 2021

Published: 11 August 2021

Citation:

Zhong $L$ and Gleason EL (2021) Adenylate Cyclase 1 Links

Calcium Signaling to

CFTR-Dependent Cytosolic Chloride

Elevations in Chick Amacrine Cells.

Front. Cell. Neurosci. 15:726605. doi: 10.3389/fncel.2021.726605

\section{Adenylate Cyclase 1 Links Calcium Signaling to CFTR-Dependent Cytosolic Chloride Elevations in Chick Amacrine Cells}

\author{
Li Zhong and Evanna L. Gleason* \\ Department of Biological Sciences, Louisiana State University, Baton Rouge, LA, United States
}

The strength and sign of synapses involving ionotropic GABA and glycine receptors are dependent upon the $\mathrm{Cl}^{-}$gradient. We have shown that nitric oxide (NO) elicits the release of $\mathrm{Cl}^{-}$from internal acidic stores in retinal amacrine cells (ACs); temporarily altering the $\mathrm{Cl}^{-}$gradient and the strength or even sign of incoming GABAergic or glycinergic synapses. The underlying mechanism for this effect of NO requires the cystic fibrosis transmembrane regulator (CFTR) but the link between NO and CFTR activation has not been determined. Here, we test the hypothesis that NO-dependent $\mathrm{Ca}^{2+}$ elevations activate the $\mathrm{Ca}^{2+}$-dependent adenylate cyclase 1 (AdC1) leading to activation of protein kinase A (PKA) whose activity is known to open the CFTR channel. Using the reversal potential of GABA-gated currents to monitor cytosolic $\mathrm{Cl}^{-}$, we established the requirement for $\mathrm{Ca}^{2+}$ elevations. Inhibitors of $\mathrm{AdC} 1$ suppressed the $\mathrm{NO}$-dependent increases in cytosolic $\mathrm{Cl}^{-}$whereas inhibitors of other $\mathrm{AdC}$ subtypes were ineffective suggesting that AdC1 is involved. Inhibition of PKA also suppressed the action of NO. To address the sufficiency of this pathway in linking NO to elevations in cytosolic $\mathrm{Cl}^{-}$, GABA-gated currents were measured under internal and external zero $\mathrm{Cl}^{-}$conditions to isolate the internal $\mathrm{Cl}^{-}$store. Activators of the cAMP pathway were less effective than $\mathrm{NO}$ in producing GABA-gated currents. However, coupling the CAMP pathway activators with the release of $\mathrm{Ca}^{2+}$ from stores produced GABA-gated currents indistinguishable from those stimulated with NO. Together, these results demonstrate that cytosolic $\mathrm{Ca}^{2+}$ links NO to the activation of CFTR and the elevation of cytosolic $\mathrm{Cl}^{-}$.

Keywords: adenylate cyclase 1, cAMP, CFTR, nitric oxide, $\mathrm{Ca}^{2+}$, amacrine cell, GABAergic neuron

\section{INTRODUCTION}

Retinal amacrine cells (ACs) are interneurons located in the inner plexiform layer (IPL) where they make synaptic contacts with bipolar cells, ganglion cells, and other ACs. Most ACs are either GABAergic or glycinergic and affect excitatory synapses via presynaptic inhibition with output to bipolar cell synaptic terminals and postsynaptic inhibition onto ganglion cell dendrites and AC 
processes (MacNeil and Masland, 1998; Grimes, 2012; Diamond, 2017). Inhibition occurs when GABA or glycine binds to the ionotropic receptors which are ligand-gated $\mathrm{Cl}^{-}$channels. The electrochemical gradient of $\mathrm{Cl}^{-}$across the plasma membrane determines the postsynaptic voltage response because the membrane potential moves to the equilibrium potential for $\mathrm{Cl}^{-}$when GABA- or glycine-gated channels are open. Because the equilibrium potential for $\mathrm{Cl}^{-}$is largely determined by the cytosolic $\mathrm{Cl}^{-}$concentration, regulation of cytosolic $\mathrm{Cl}^{-}$is a key determinant of the strength and even sign of GABAergic and glycinergic synapses.

$\mathrm{Cl}^{-}$cotransporter is a well-known mechanism that regulates cytosolic $\mathrm{Cl}^{-}$concentration (Ben-Ari et al., 2012). The chloride cotransporters $\mathrm{Na}-\mathrm{K}-2 \mathrm{Cl}$ (NKCC) and $\mathrm{K}-\mathrm{Cl}$ (KCC) modulate the neuronal response to GABA and glycine by determining intracellular $\mathrm{Cl}^{-}$level using the $\mathrm{Na}^{+}$and $\mathrm{K}^{+}$gradients, respectively (Russell, 2000; Delpire and Mount, 2002; Payne et al., 2003; Gamba, 2005). Previous work in our lab has shown that nitric oxide (NO) can stimulate the release of $\mathrm{Cl}^{-}$from acidic intracellular stores in ACs by a mechanism involving the cystic fibrosis transmembrane conductance regulator (CFTR; Hoffpauir et al., 2006; Krishnan and Gleason, 2015; Krishnan et al., 2017).

CFTR is a $\mathrm{Cl}^{-}$channel that has two membrane spanning domains (MSD), two cytosolic nucleotide binding domains (NBD), and a regulatory domain (RD) that contains numerous phosphorylation sites. It is encoded by the CFTR gene and mutations in this gene cause the deleterious effects observed in cystic fibrosis (Riordan et al., 1989; Tsui, 1992; Quinton, 1999). This disease is associated with reduced chloride permeability across the apical epithelial membrane (Quinton and Bijman, 1983; Widdicombe et al., 1985).

The chloride channel CFTR can be regulated by protein kinases and it is most strongly activated by protein kinase A (PKA; Picciotto et al., 1992; Gadsby and Nairn, 1999). CFTR can also be modulated by $\mathrm{Ca}^{2+}$ signaling as well as the cAMP pathway in epithelia (Kunzelmann and Mehta, 2013; Bozoky et al., 2017). Instead of stimulating the CFTR channel directly, $\mathrm{Ca}^{2+}$ can activate calcium-dependent adenylate cyclase (AdC) isoforms 1,3 , or 8, leading to the production of cAMP and activation of PKA. PKA can phosphorylate the CFTR RD and then activate the CFTR $\mathrm{Cl}^{-}$channel (Halls and Cooper, 2011; Billet and Hanrahan, 2013). All AdC isoforms can be found in the central nervous system, but AdC8 is the least abundant (Xia et al., 1991; Mons et al., 1993). Although AdC3 is $\mathrm{Ca}^{2+} /$ Calmodulinactivated, the sensitivity to $\mathrm{Ca}^{2+}$ is 100 times lower than that of $\mathrm{AdC} 1$ and activation requires the presence of other effectors such as forskolin or an activator of $\mathrm{G}$ proteins in human embryonic kidney 293 cells (Choi et al., 1992). The resting concentration of intracellular free $\mathrm{Ca}^{2+}$ in neurons typically ranges between 50 and $100 \mathrm{nM}$ which matches the range of free $\mathrm{Ca}^{2+}$ producing half-maximal activation of AdC1 (Choi et al., 1992; Villacres et al., 1995; Masada et al., 2009).

We have previously demonstrated that NO leads to a CFTR-dependent release of internal $\mathrm{Cl}^{-}$(Krishnan et al., 2017). However, the mechanism underlying this effect was unknown. In a previous study on the regulation of L-type $\mathrm{Ca}^{2+}$ channels in
ACs, we learned that AdC1 is expressed in both cell bodies and cell processes of ACs in culture (Tekmen and Gleason, 2010). We have also reported that $\mathrm{NO}$ can increase cytosolic $\mathrm{Ca}^{2+}$ (Maddox and Gleason, 2017). Another possibility is that NO directly activates CFTR via s-nitrosylation. Analysis of the chicken CFTR sequence with the bioinformatics program RecSNO (Siraj et al., 2021) predicts nine likely s-nitrosylation sites. However, our observation of $\mathrm{NO}$-dependent $\mathrm{Ca}^{2+}$ elevations leads us to prioritize investigating the role of $\mathrm{AdC} 1$. Hence, we hypothesized that the $\mathrm{NO}$-generated $\mathrm{Ca}^{2+}$ elevations in ACs activate $\mathrm{AdC1}$, produce elevations in CAMP, and ultimately phosphorylation and activation of CFTR via PKA.

To test this hypothesis, whole-cell voltage clamp recording was used to monitor changes in $\mathrm{AC}$ cytosolic $\mathrm{Cl}^{-}$and $\mathrm{Ca}^{2+}$ imaging was used for monitoring cytosol $\mathrm{Ca}^{2+}$ concentration. We found that $\mathrm{NO}$-dependent release of internal $\mathrm{Cl}^{-}$was inhibited when either cytosolic $\mathrm{Ca}^{2+}$ was buffered by BAPTA or the cAMP pathway was suppressed by inhibitors. These data suggest that $\mathrm{Ca}^{2+}$ is crucial for NO-dependent release of $\mathrm{Cl}^{-}$and it activates cAMP pathway through activation of AdC1.

\section{MATERIALS AND METHODS}

\section{Cell Culture}

Retinas were dissected from 8-day chick embryos, and cells were plated on poly-L-Ornithine pre-processing dishes. Cells were first plated with Dulbecco's modified Eagle's medium (DMEM; Life Technologies), 5\% fetal calf serum (Sigma, St. Louis, MO, USA), $100 \mathrm{U} / \mathrm{ml}$ penicillin, $100 \mu \mathrm{g} / \mathrm{ml}$ streptomycin, and $2 \mathrm{mM}$ glutamine (Life Technologies), then fed every 2 days by replacing the media with feeding solution which contains neurobasal medium (Life Technologies), 1\% B-27 nutrient medium and penicillin-streptomycin-glutamine (Life Technologies) for 2 weeks. For further details see Maddox and Gleason (2017). The experimental ACs were identified using established morphological criteria (Gleason et al., 1993) and were used for the experiment after 7-11 days in cultures.

\section{Electrophysiology}

Culture dishes were anchored on the stage of an Olympus IX70 inverted microscope. An Ag-AgCl reference pellet electrode was submerged in $3 \mathrm{M} \mathrm{KCl}$ solution and connected to the dish through a $1 \%$ agarose salt bridge. Patch pipettes were pulled from thick-walled borosilicate glass $(1.5 \mathrm{~mm}$ outer diameter, $0.86 \mathrm{~mm}$ inner diameter) using a P-97 Flaming/Brown Puller (Sutter Instruments, Novato, CA, USA). The pipettes were chosen by a tip resistance between 8 and $12 \mathrm{M} \Omega$. Whole-cell voltage clamp recordings were performed using Axopatch $1 \mathrm{D}$ amplifier, Digidata 1322A data-acquisition board, and Clampex 10.0 (Molecular Devices, Sunnyvale, CA, USA). The external solution was pushed to the dish with a constant flow rate $1 \mathrm{ml} / \mathrm{min}$ via a pressurized 8-channel perfusion system (Automate Scientific, Berkeley, CA, USA). Data were obtained from the ACs that were not in contact with other neurons. The current-voltage relationship was corrected for series resistance and junction potential errors $(13 \mathrm{mV})$, calculated from pClamp 10.0 calculator. For voltage ramp experiments, the voltage was held at $-70 \mathrm{mV}$ 
for $150 \mathrm{~ms}$, then stepped to $-90 \mathrm{~ms}$ for $50 \mathrm{~ms}$ and ramped from $-90 \mathrm{mV}$ to $+50 \mathrm{mV}$ over $200 \mathrm{~ms}$ before stepping back to $-70 \mathrm{mV}$. Each sweep contained two ramps, the first was for measuring the leak currents for subtraction from the second ramp recorded in the presence of GABA $(20 \mu \mathrm{M})$. The total time of the protocol for each sweep was $2.7 \mathrm{~s}$. The $\mathrm{GABA}_{\mathrm{A}}$ receptor conductance was determined by calculating the slope of the current-voltage relationship from $-60 \mathrm{mV}$ to $-40 \mathrm{mV}$.

For GABA pulse experiments, the voltage was held at $-70 \mathrm{mV}$ for $9.5 \mathrm{~s}$, then exposed to GABA $(20 \mu \mathrm{M})$ for $400 \mathrm{~ms}$. Each sweep contained five GABA pulses and the total time of the sweep was $29 \mathrm{~s}$. The largest GABA pulse response was chosen for analysis. The GABA-gated current amplitude with treatment was calculated by subtracting the control GABA-gated current with no test treatment. Each replicate indicates an individual cell. The experiments in Figure 5 (NO vs. cAMP ct) and in Figure 8D (NO vs. cAMP ct + ionomycin) were analyzed with the same $\mathrm{NO}$ control group because the experiments were done on the same group of cells. The external solution and GABA containing external solution flowed into the test dish through fast-step perfusion system SF-77C via 3-barrel square glass (Warner Instruments, Hamden, CT, USA). All experiments were performed at room temperature.

\section{Solutions}

All components were purchased from Sigma-Aldrich (St. Louis, MO, USA) unless otherwise indicated. The normal external solution contained (in $\mathrm{mM}$ ): $\mathrm{NaCl}$ (116.7), $\mathrm{KCl}$ (5.3), tetrathylammonium (TEA)-Cl (20.0), $\mathrm{CaCl}_{2}$ (3), $\mathrm{MgCl}_{2}$ (0.41), glucose (5.6), HEPES (10.0), $\mathrm{pH}$ adjusted to 7.4 with $\mathrm{NaOH}$. For voltage ramp recordings, Tetrodotoxin citrate (TTX; $300 \mathrm{nM}$, Abcam, Cambridge, UK) and $\mathrm{La}^{3+}(50 \mu \mathrm{M})$ were added to block voltage-gated $\mathrm{Na}^{+}$and $\mathrm{Ca}^{2+}$ currents, respectively. The normal internal solution contained (in $\mathrm{mM}$ ): Cs-acetate (100.0), $\mathrm{CsCl}$ (10.0), $\mathrm{CaCl}_{2}$ (0.1), $\mathrm{MgCl}_{2}$ (2.0), HEPES (10.0), and EGTA (1.0), pH adjusted to 7.4 with $\mathrm{CsOH}$. For GABA pulse experiments, zero $\mathrm{Cl}^{-}$external solution was made with (in $\mathrm{mM}$ ): Na-methanesulfonate (145.0), glucose (5.6), and 10.0 HEPES, $\mathrm{pH}$ adjusted to 7.4 with $\mathrm{NaOH}$. The zero $\mathrm{Cl}^{-}$internal solution was made with (in $\mathrm{mM}$ ): Cs-methanesulfonate (125.0) and HEPES (10.0), $\mathrm{pH}$ adjusted to 7.4 with $\mathrm{CsOH}$. The agarose salt bridge was placed close to the outflow in order to minimize $\mathrm{Cl}^{-}$leaking onto ACs during recording. For $\mathrm{Ca}^{2+}$ imaging experiments, zero $\mathrm{Ca}^{2+}$ external solution contained (in $\mathrm{mM}$ ): $\mathrm{NaCl}$ (141.5), $\mathrm{KCl}$ (5.37), $\mathrm{MgCl} 2$ (0.41), glucose (5.6), HEPES (3.02), $\mathrm{pH}$ adjusted to 7.4 with $\mathrm{NaOH}$. For all electrophysiological experiments, the internal solution was supplemented with an ATP regeneration system containing creatine phosphokinase $(50 \mathrm{U} / \mathrm{ml})$, creatine phosphate $(20 \mathrm{mM})$, ATP disodium $(1 \mathrm{mM})$, ATP dipotassium (3 $\mathrm{mM})$, and GTP disodium $(2 \mathrm{mM})$. The NO-saturated solution was prepared by bubbling Fisher ultra-distilled pure water with argon for $15 \mathrm{~min}$, then bubbled with pure NO gas for $15 \mathrm{~min}$. NO solution was delivered by injection into the external solution perfusion line. The concentration of NO at the perfusion outlet was in the 100's nM-low $\mu \mathrm{M}$ range. NO $(30-50 \mu \mathrm{l})$ has been estimated to reach the recorded cell in $\sim 3$ s and to remain for $\sim 3-5$ s (Hoffpauir et al., 2006).

\section{Reagents}

All reagents were purchased from Tocris (Bristol, UK). The 1,2-Bis(2-aminophenoxy)ethane-N,N, $\mathrm{N}^{\prime}, \mathrm{N}^{\prime}$-tetraacetic acid tetrakis (acetoxymethyl ester; BAPTA, $50 \mu \mathrm{M}$ ) was prepared as a $50 \mathrm{mM}$ stock in DMSO and diluted in internal solution. The AdC inhibitor (SQ 22536, 100 nM), AdC 1 inhibitor (ST 034307, $100 \mathrm{nM}$ ), AdC2 inhibitor (SKF 83566 hydrobromide, $10 \mu \mathrm{M})$, AdC 5/3 inhibitor 2-Amino7-(2-furanyl)-7,8-dihydro-5(6H)-quinazolinone (NKY 80, $200 \mu \mathrm{M})$, PKA inhibitor $N$-[2-[[3-(4-Bromophenyl)2-propenyl]amino]ethyl]-5-isoquinolinesulfonamide

dihydrochloride (H89 dihydrochloride, $1 \mu \mathrm{M}$ ) and selective PKA inhibitor (KT 5720, $300 \mathrm{nM}$ ) were prepared as $1,000 \times$ stocks in DMSO and diluted to $1 \times$ in the external solution. Cells were preincubated with inhibitors at $37^{\circ} \mathrm{C}$ in $5 \%$ $\mathrm{CO}_{2}$ for 20-30 min before recording. The Cell-permeable cAMP analog (8-Bromo-cAMP, sodium salt, $100 \mu \mathrm{M})$, the phosphodiesterase inhibitor (non-selective; 3-Isobutyl-1methylxanthine, $20 \mu \mathrm{M})$, and AdC activator forskolin $(1 \mu \mathrm{M})$ were prepared as $1,000 \times$ stocks in DMSO and diluted to $1 \times$ in the external solution. 8-Bromo-cAMP, IBMX, and forskolin were applied during recording via the perfusion. The calcium ionophore (ionomycin, $5 \mu \mathrm{M}$ ) was prepared as a $5 \mathrm{mM}$ stock in DMSO and diluted in the external solution.

\section{Calcium Imaging}

The cell-permeable fluorescence $\mathrm{Ca}^{2+}$ indicator Oregon Green 488 Bapta-1, AM (OGB, $2 \mu \mathrm{M}$, Life Technologies, Grand Island, NY) stock solution ( $2 \mathrm{mM})$ was mixed with Pluronic F-127 (2.5\% w/v in DMSO, Life Technologies) 1:1 sonicated, then $2 \mu \mathrm{l}$ was added to $1 \mathrm{ml}$ of Hank's buffered saline solution (HBSS), vortexed and sonicated for $30 \mathrm{~s}$ to produce the loading solution. The culture media was replaced with OGB in HBSS and cells were incubated for $1 \mathrm{~h}$ at room temperature. For zero $\mathrm{Ca}^{2+}$ experiments, the perfusion was switched to zero $\mathrm{Ca}^{2+}$ external solution prior to the start of the recording. Images were taken every $3 \mathrm{~s}$ with $1 \mathrm{~s}$ exposure time on an inverted Olympus IX70 microscope (Center Valley, PA) fitted with a SensiCam QE (Cooke, Kelheim, Germany). Data were collected from regions of interest (ROIs) in ACs bodies and cell processes. For analysis of the effect of NO, the mean value of the control group was calculated by taking the average of the last $30 \mathrm{~s}$ before NO application, the mean value of the NO group was calculated by taking the average of the middle $30 \mathrm{~s}$ during $\mathrm{NO}$ application. The average of data points from $150 \mathrm{~s}$ to $177 \mathrm{~s}$ was the mean value for the wash group. The mean peak fluorescence change was calculated by subtracting the mean of baseline fluorescence intensity (30 s before NO response) from the peak NO response for data from each ROI. For analysis of the effect of ionomycin, the means of all data points collected before, and during ionomycin application were calculated. Wash data were calculated from a window of time from $93 \mathrm{~s}$ to $120 \mathrm{~s}$. 
Images acquisition and analysis were achieved using Slidebook 5.0 software.

\section{Data Analysis}

Analysis of voltage ramps experiments, the current and voltage relationships were calculated and plotted in Origin 8.0 (OriginLab, Northampton, MA, USA). Clampfit 10.0 software was used to exhibit the sweep traces and analyze the currents. Analysis of GABA pulse experiments, GABA-gated inward currents were displayed in Clampfit 10.0 and filtered with Gaussian low pass at $300 \mathrm{~Hz}$. Data were calculated and plotted in Origin 8.0. Calcium imaging data were analyzed in Slidebook 5.0. All the descriptive statistics, unpaired $t$-tests, paired $t$-tests, Welch's $t$-tests and ANOVA were performed on Prism 8 (GraphPad Software, La Jolla, CA, USA). Data were reported as means \pm SEM. The $P$-value of significance was $<0.05$.

\section{RESULTS}

\section{NO Releases $\mathrm{Ca}^{2+}$ From Stores}

We have previously shown that the NO donor SNAP can enhance intracellular $\mathrm{Ca}^{2+}$ in ACs via activation of transient receptor potential canonical channel 5 (TRPC5; Maddox and Gleason, 2017; Maddox et al., 2018). To confirm the NO-bubbled external solution also elevates $\mathrm{Ca}^{2+}$ levels, cells were loaded with Oregon Green BAPTA-1 488-AM (OGB, $2 \mu \mathrm{M}$ ) and fluorescence intensity was monitored over time. With application of NO in normal external solution, the intracellular $\mathrm{Ca}^{2+}$ increased by about 12\% (control, 1,736 \pm 133.4 A.U.; NO, $1943 \pm 140.5$ A.U.; $n=45 ; p<0.0001$, paired $t$-test, Figures 1A,B). To determine whether this $\mathrm{NO}$ exposure could elicit the release of $\mathrm{Ca}^{2+}$ from stores, $\mathrm{Ca}^{2+}$ was removed from the external solution. NO elicited a $28 \%$ cytosolic $\mathrm{Ca}^{2+}$ elevation in the absence of extracellular $\mathrm{Ca}^{2+}$ (control, $1,441 \pm 97.1$ A.U.; NO, $1848 \pm 109$ A.U.; $n=54 ; p<0.0001$, paired $t$-test, Figures 1C,D). After subtracted baseline fluorescence, cells in zero $\mathrm{Ca}^{2+}$ extracellular condition had higher cytosolic $\mathrm{Ca}^{2+}$ increase than that in normal external condition (normal external, $266.1 \pm 23.2$ A.U.; $n=45$; zero $\mathrm{Ca}^{2+}$ external, $406.8 \pm 26.1$ A.U.; $n=54 ; p<0.001$, unpaired $t$-test, Figure 1E). However, the maximum NO responses in normal and zero $\mathrm{Ca}^{2+}$ external were not statistically different (normal external, 2,002 \pm 141.2 A.U.; $n=45$; zero $\mathrm{Ca}^{2+}$ external, $1,848 \pm 109$ A.U.; $n=54 ; p=0.38$, unpaired $t$-test, Figure 1F). The higher magnitude of change NO-dependent cytosolic $\mathrm{Ca}^{2+}$ in zero $\mathrm{Ca}^{2+}$ external is due to the lower resting cytosolic $\mathrm{Ca}^{2+}$ level (normal external, $1,808 \pm 131.7$ A.U.; $n=45$; zero $\mathrm{Ca}^{2+}$ external, 1,460 \pm 94.2 A.U.; $n=54 ; p<0.05$, unpaired $t$ test, Figure 1G). The decay time constant in normal external was larger than that in zero $\mathrm{Ca}^{2+}$ external condition, suggesting that the latter part of the response was more dependent upon extracellular $\mathrm{Ca}^{2+}$, consistent with activation of TRPC5 (Maddox et al., 2018; normal external, $213.8 \pm 22.9 \mathrm{~s}, n=33$; zero $\mathrm{Ca}^{2+}$ external, $45.8 \pm 6.2 \mathrm{~s}, n=49 ; p<0.0001$, unpaired $t$-test, Figure $\mathbf{1 H}$ ). Together, these results suggest that NO-bubbled solutions can elicit both $\mathrm{Ca}^{2+}$ influx across the plasma membrane and release of $\mathrm{Ca}^{2+}$ from internal stores.

\section{$\mathrm{Ca}^{2+}$ Elevations Are Required for the NO-Dependent Release of Internal $\mathrm{Cl}^{-}$}

To determine whether the elevation in cytosolic $\mathrm{Ca}^{2+}$ is required for the release of internal $\mathrm{Cl}^{-}$, the effect of BAPTA was tested. To estimate cytosolic $\mathrm{Cl}^{-}$concentration, the NO-dependent shift in the reversal potential of GABA-gated current ( $\mathrm{E}_{\mathrm{REV} \text {-GABA }}$ ) was determined by delivering voltage ramps during the application of GABA to activate $\mathrm{GABA}_{\mathrm{A}}$ receptors. As previously demonstrated with gramicidin perforated-patch recordings (Hoffpauir et al., 2006), the resting intracellular $\mathrm{Cl}^{-}$level is relatively low in ACs and similar to our pipette solution $\mathrm{Cl}^{-}$concentration. $\mathrm{E}_{\mathrm{REV}-\mathrm{GABA}}$ was determined before and after $\mathrm{NO}$ to track cytosolic $\mathrm{Cl}^{-}$ concentration changes. Under control conditions, the reversal potential had a positive shift with $\mathrm{NO}$, indicating an increase in cytosolic $\mathrm{Cl}^{-}$(control, $32.7 \pm 2.8 \mathrm{mV}, n=6$, Figure $2 \mathrm{~A}$ ). The $\mathrm{Ca}^{2+}$ chelator BAPTA $(50 \mu \mathrm{M})$ was applied via the recording pipette. In cells loaded with BAPTA, the NO-dependent reversal potential shift was strongly inhibited (BAPTA, $1.7 \pm 1.6 \mathrm{mV}$, $P<0.0001, n=5$, Figures 2B,C). These results indicated that calcium elevations are required for the $\mathrm{NO}$-dependent release of internal $\mathrm{Cl}^{-}$.

\section{Only AdC1 Inhibitors Suppress the NO-Dependent Release of $\mathrm{Cl}^{-}$}

To investigate the involvement of $A d C 1$ in release of $\mathrm{Cl}^{-}$ from the internal store, the effects of AdC inhibitors were examined. SQ22536 (100 nM), a general AdC inhibitor, suppressed the shift in $\mathrm{E}_{\mathrm{REV}-\mathrm{GABA}}$ (control shift, $38.2 \pm 1.9 \mathrm{mV}$; SQ22536 shift, $9.7 \pm 3.0 \mathrm{mV}$; $n=11$ for both groups; $p<0.0001$, unpaired $t$-test, Figures 3A,B). The AdC1 inhibitor, ST034307 (100 nM) was also effective; providing evidence for the involvement of $\mathrm{AdC1}$, specifically (control shift, $31.0 \pm 3.4 \mathrm{mV}$; ST 034307 shift, $13.1 \pm 2.6 \mathrm{mV} ; n=9$ each; $p<0.001$, unpaired $t$-test, Figures 3C,D). Neither the AdC2 inhibitor SKF83566 (10 $\mu \mathrm{M})$ nor the AdC3 and 5 inhibitor (NKY 80, $200 \mu \mathrm{M}$ ) inhibited the NO-dependent shift in $\mathrm{E}_{\mathrm{REV}-\mathrm{GABA}}$ (control shift, $41.5 \pm 3.9 \mathrm{mV}, n=11$; SKF83566 shift, $42.1 \pm 3.0 \mathrm{mV}$, $n=10 ; p=0.9079$; control shift, $47.3 \pm 4.6 \mathrm{mV}, n=7$; NKY 80 shift, $38.7 \pm 2.8, n=8 ; p=0.1254$; unpaired $t$-tests, Figures $3 \mathrm{E}-\mathbf{H})$. Together, these results suggest that $\mathrm{AdC1}$, specifically, is involved in the NO-dependent internal $\mathrm{Cl}^{-}$ release.

\section{PKA Inhibitors Disrupt the NO-Dependent Release of Internal $\mathrm{Cl}^{-}$}

To examine the role of PKA in determining cytosolic $\mathrm{Cl}^{-}$ concentration, two PKA inhibitors (H89 $1 \mu \mathrm{M}$, KT5720 $300 \mathrm{nM}$ ) were employed. Both inhibitors were effective in suppressing the $\mathrm{NO}$-dependent internal $\mathrm{Cl}^{-}$release (control shift, $30.2 \pm 3.1 \mathrm{mV}$; H89 shift, $12.3 \pm 4.8 \mathrm{mV}$, preincubated for $30 \mathrm{~min} ; n=9$ for both groups; $p<0.01$, unpaired $t$ test, Figures 4A,B; control shift, $38.8 \pm 1.7 \mathrm{mV}, n=9$; KT5720 shift, $9.8 \pm 4.2 \mathrm{mV}$, preincubated for $20 \mathrm{~min}$, $n=8 ; p<0.0001$, Welch's unpaired $t$-test, Figures 4C,D). In addition, there is evidence that PKA directly modulates 
A

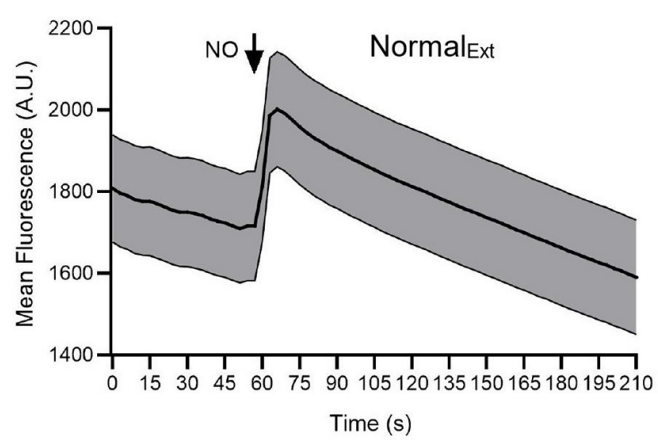

C

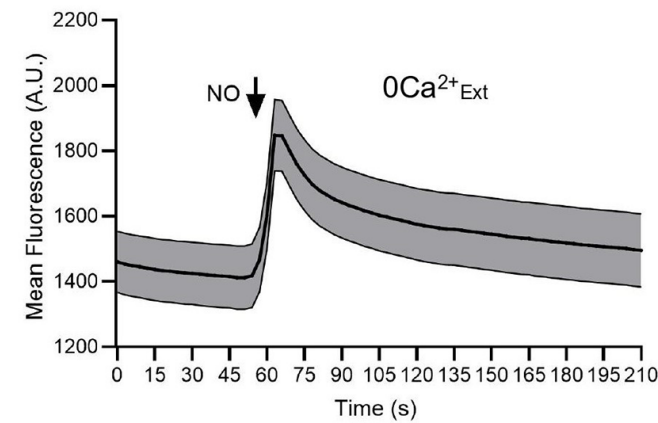

E

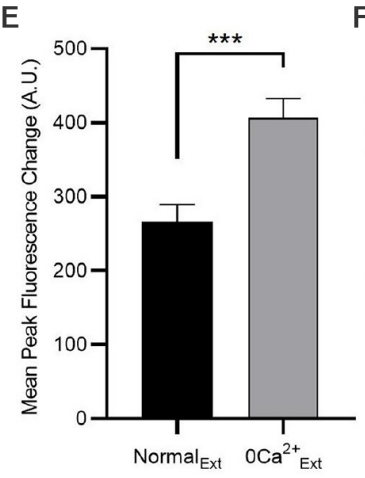

B

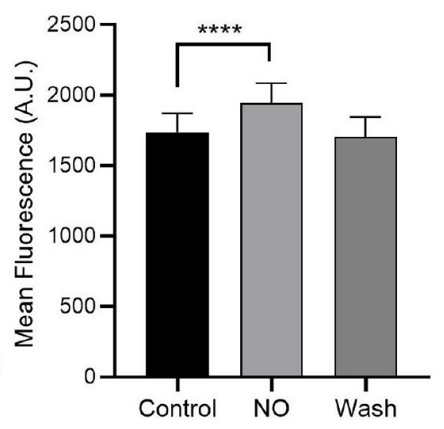

D

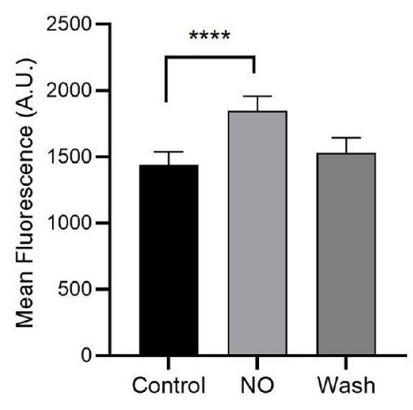

G

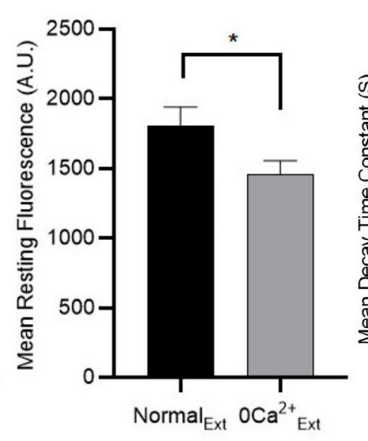

H

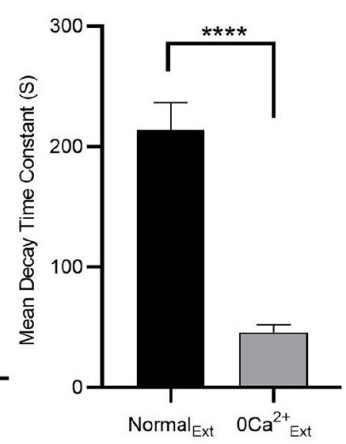

FIGURE 1 | NO increases cytosolic $\mathrm{Ca}^{2+}$ concentration. Fluorescence intensity measurements from ACs loaded with Oregon Green BAPTA-1 488-AM are shown (A,C). (A) In the normal external solution, NO produces an increase in cytosolic $\mathrm{Ca}^{2+}$. (B) The quantified mean fluorescence $\pm \mathrm{SEM} ; n=45$. ${ }^{* * * *} P<0.0001$ (paired $t$-test). (C) In the absence of $\mathrm{Ca}^{2+}\left(0 \mathrm{Ca}^{2+}\right.$ Ext), NO increases cytosolic $\mathrm{Ca}^{2+}$. (D) The quantified mean fluorescence $\pm \mathrm{SEM} ; n=54$. ${ }^{* * * *} P<0.0001$ (paired $t$-test). (E) The quantified mean peak fluorescence $\pm \mathrm{SEM}$ after subtracting baseline in normal external condition, $n=45$ and in zero $\mathrm{Ca}^{2+}$ external condition, $n=54$. ${ }^{\star \star \star} P<0.001$ (unpaired $t$-test). (F) The quantified mean peak fluorescence \pm SEM in normal external condition, $n=45$ and in zero Ca ${ }^{2+}$ external condition, $n=54$. $P=0.38$ (unpaired $t$-test). (G) The quantified mean resting fluorescence \pm SEM in normal external condition, $n=45$ and in zero Ca ${ }^{2+}$ external condition, $n=54$. ${ }^{*} P<0.05$ (unpaired $t$-test). (H) The quantified mean decay time constant \pm SEM in normal external condition, $n=33$ and in zero Ca ${ }^{2+}$ external condition, $n=49$. Data for each cell are fitted with one phase decay exponential curve. ${ }^{\star \star \star \star} P<0.0001$ (unpaired $t$-test).

$\mathrm{GABA}_{\mathrm{A}}$ receptors in multiple cell types including retinal neurons (Porter et al., 1990; Wong and Moss, 1992; Feigenspan and Bormann, 1994; Veruki and Yeh, 1994; Wexler et al., 1998). To test this possibility that inhibition of PKA might affect the $\mathrm{GABA}_{\mathrm{A}}$ receptor itself by altering mean open time or receptor sensitivity, we compared the conductance of the GABA-gated current in control and KT5720 pretreatment conditions. No effects of PKA inhibition on the conductance were observed (control, $7.72 \pm 0.58 \mathrm{nS}$, $n=9$; KT5720, $8.98 \pm 0.77 \mathrm{nS}, n=8 ; p=0.2057$, unpaired $t$-tests, Figure $4 \mathrm{E})$. In sum, these results indicate a role for AdC1-dependent signaling via cAMP and PKA in the activation of CFTR.

\section{Elevating cAMP in the Absence of NO Promotes $\mathrm{Cl}^{-}$Release From the Internal Store}

If AdC1 and PKA are sufficient for the release of $\mathrm{Cl}^{-}$from internal stores, we should be able to bypass $\mathrm{NO}$ and directly 
A

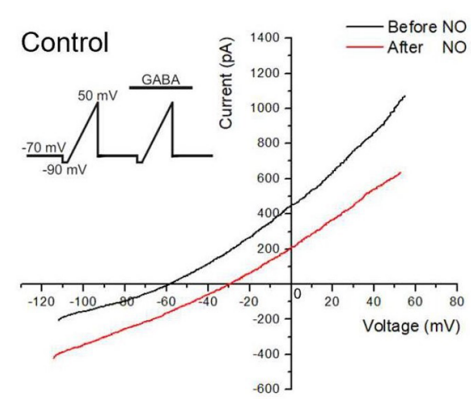

B

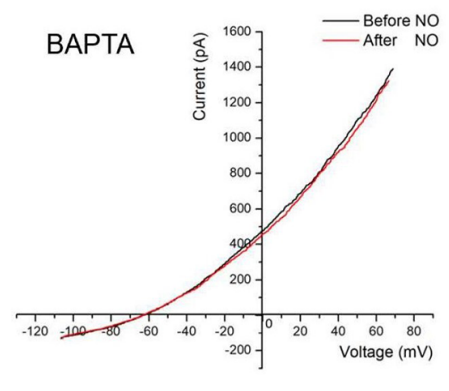

C

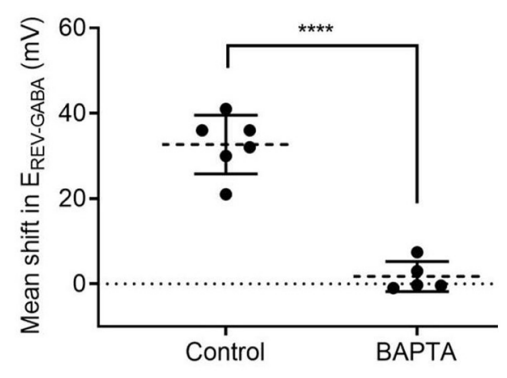

FIGURE 2 | Calcium elevations are required for the NO-dependent release of internal $\mathrm{Cl}^{-}$. (A,B) The current-voltage relationship for the GABA-gated current (20 $\mu \mathrm{M})$ before and after NO. Inset shows the voltage ramp protocol with GABA delivered during the second ramp. Under control conditions, $E_{\mathrm{REV}-\mathrm{GABA}}$ shifts to the right. With the $\mathrm{Ca}^{2+}$ chelator, BAPTA $(50 \mu \mathrm{M})$ in the recording pipette, NO fails to elicit the $E_{\text {REV-GABA }}$ shift. (C) The quantified mean shift in $E_{\text {REV }}$ GABA \pm SEM; control, $n=6$; BAPTA, $n=5 .{ }^{* * * *} P<0.0001$ (unpaired $t$-test).

activate the cAMP pathway to release $\mathrm{Cl}^{-}$into the cytosol. To achieve this, we used a combination of reagents to create a cAMP "cocktail" (cAMP ct) composed of the AdC activator, forskolin (1 $\mu \mathrm{M})$; the cAMP analog, 8-bromo-cAMP (100 $\mu \mathrm{M})$, and the phosphodiesterase inhibitor, IBMX $(20 \mu \mathrm{M})$. To maximize our ability to detect $\mathrm{Cl}^{-}$release and to ensure that we were measuring $\mathrm{Cl}^{-}$originating from the internal store, we employed an alternative experimental strategy. GABA-gated currents were recorded in $\mathrm{Cl}^{-}$-free internal and external solutions. Because $\mathrm{E}_{\mathrm{REV}-\mathrm{GABA}}$ is not measurable under these conditions, cells were held at $-70 \mathrm{mV}$ and GABA $(20 \mathrm{mM})$ was applied for $400 \mathrm{~ms}$ (five times /sweep). GABA-gated inward currents were initially very small then disappeared completely as the $\mathrm{Cl}^{-}$-free pipette solution washed out residual $\mathrm{Cl}^{-}$from the cell. After $\mathrm{NO}$, however, GABA-gated inward currents were observed indicating that sequestered $\mathrm{Cl}^{-}$had been released into the cytosol and then exited via open $\mathrm{GABA}_{\mathrm{A}}$ receptors on the plasma membrane (Figure 5A).

The cAMP pathway inhibitor experiments suggest that activation of the CAMP pathway is necessary for the NO-dependent shift in $E_{R E V-G A B A}$. To test whether cAMP pathway activity is sufficient, cells were exposed to cAMP ct designed to elevate cAMP levels and PKA activity. In the GABA pulse experiment, the cAMP ct generated a small inward GABA-gated current (Figure 5B). Although the GABA responses were elicited by cAMP ct, they were significantly smaller than those recorded in response to NO (Figure 5C). These results indicate that elevating cAMP signaling alone has a small effect on releasing $\mathrm{Cl}^{-}$from internal store $(\mathrm{NO},-13.1 \pm 2.6 \mathrm{pA}, n=13$; cAMP ct $-6.5 \pm 0.9 \mathrm{pA}, n=14 ; p<0.05$, Welch's unpaired $t$-test).

\section{Activation of Voltage-Gated $\mathrm{Ca}^{2+}$ Channels Does Not Elicit $\mathrm{Cl}^{-}$Release}

The activity of AdC1 relies on $\mathrm{Ca}^{2+}$. To determine whether a $\mathrm{Ca}^{2+}$ elevation alone is sufficient to activate the pathway and cause the release of internal $\mathrm{Cl}^{-}$, a series of 10 sweeps, $100 \mathrm{~ms}$ voltage steps from $-70 \mathrm{mV}$ to $0 \mathrm{mV}$ of each sweep were delivered after the GABA pulse control sweeps (Figures 6B,C). For these experiments, $3 \mathrm{mM} \mathrm{Ca}^{2+}$ was added to the external solution (Figure 6C). After the voltage steps, subsequent GABA pulses did not elicit inward currents (NO control, $-20.2 \pm 3.8 \mathrm{pA}$, $n=10 ; 0 \mathrm{Ca}^{2+}$ control, $-0.4 \pm 0.7 \mathrm{pA}, n=9 ; \mathrm{Ca}^{2+},-0.8 \pm 0.4 \mathrm{pA}$, $n=8 ; p=0.6$, repeated-measures ANOVA, Figures 6A-D). These results suggest that $\mathrm{Ca}^{2+}$ influx via voltage-gated $\mathrm{Ca}^{2+}$ channels is not effective in activating efflux of $\mathrm{Cl}^{-}$from internal stores.

\section{Ionomycin Releases $\mathrm{Ca}^{2+}$ From Internal Stores in the Absence of Extracellular $\mathrm{Ca}^{2+}$}

If the influx of $\mathrm{Ca}^{2+}$ through voltage-gated $\mathrm{Ca}^{2+}$ channels is ineffective in elevating cytosolic $\mathrm{Cl}^{-}$but $\mathrm{Ca}^{2+}$ elevations are required, perhaps it is $\mathrm{Ca}^{2+}$ released from internal stores specifically, that links $\mathrm{NO}$ to $\mathrm{Cl}^{-}$efflux. To test this, we first confirmed that we could use ionomycin in $\mathrm{Ca}^{2+}$-free external solution to elicit the release from $\mathrm{Ca}^{2+}$ stores. OGB-loaded ACs were monitored during exposure to ionomycin $(5 \mu \mathrm{M})$. Data were captured in AC cell bodies and cell processes. With ionomycin, intracellular $\mathrm{Ca}^{2+}$ increased by about $21 \%$ and 9.8\% in cell bodies and processes, respectively (cell bodies: control, $132.3 \pm 9.3$ A.U.; ionomycin $160 \pm 13$ A.U.; $n=73$; $p<0.0001$, paired $t$-test, Figures 7A,B; cell processes: control, $18.3 \pm 1.6$ A.U.; ionomycin $20.1 \pm 2.0$ A.U.; $n=58 ; p<0.01$, paired $t$-test, Figures 7C,D). These data show that ionomycin is effective in releasing store $\mathrm{Ca}^{2+}$ in ACs.

\section{Pairing Elevated cAMP and $\mathrm{Ca}^{2+}$ Release Mimics the Effects of NO}

To test whether the release of store $\mathrm{Ca}^{2+}$ can stimulate $\mathrm{Cl}^{-}$release from the $\mathrm{Cl}^{-}$internal store, GABA pulse data were gathered before and after exposure to ionomycin. These experiments were done in the absence of internal and external $\mathrm{Cl}^{-}$, and external $\mathrm{Ca}^{2+}$. With the addition of ionomycin $(5 \mu \mathrm{M})$, small GABA-gated inward currents were elicited but were significantly smaller than those elicited by $\mathrm{NO}(\mathrm{NO},-12.1 \pm 1.7 \mathrm{pA}, n=7$; ionomycin, $-7.1 \pm 0.7 \mathrm{pA}, n=11 ; p<0.01$, unpaired $t$ - 


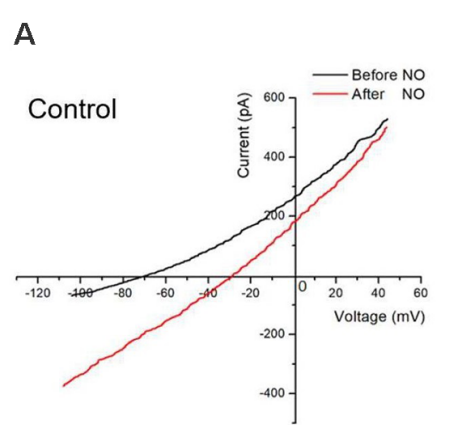

C

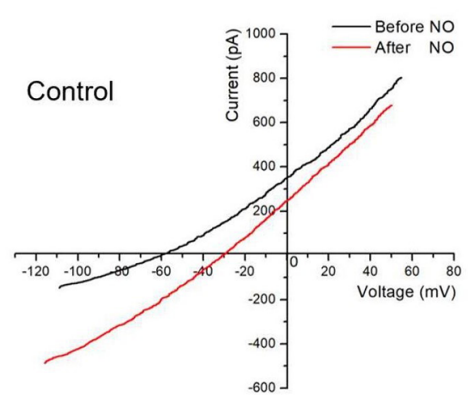

E

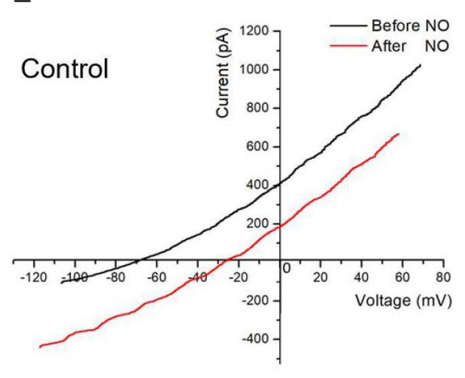

G

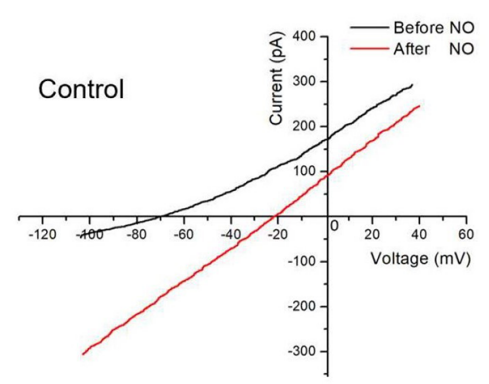

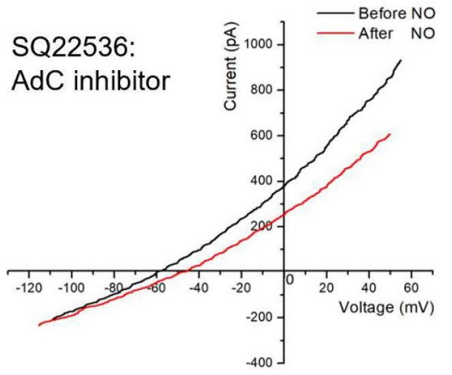

B

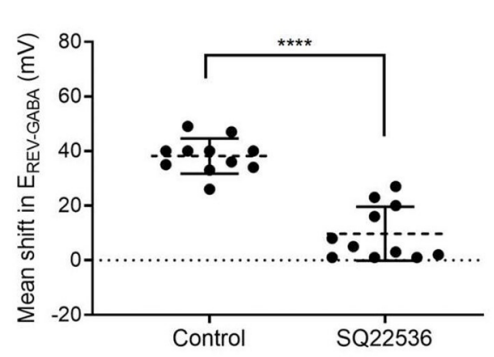

D
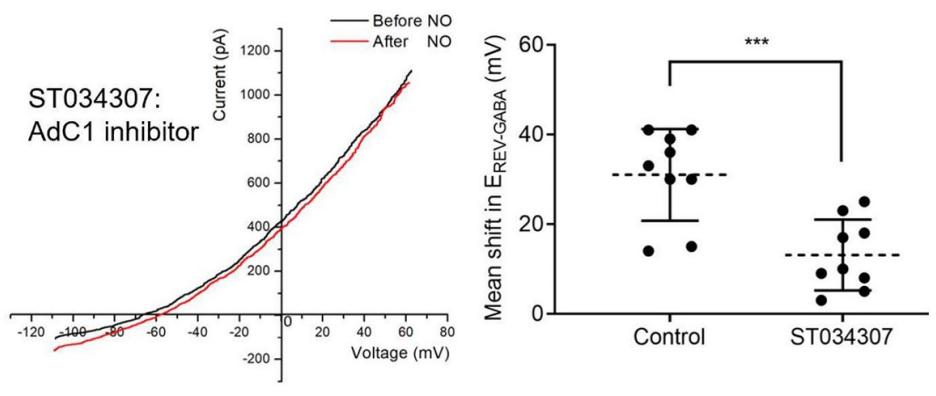

$F$
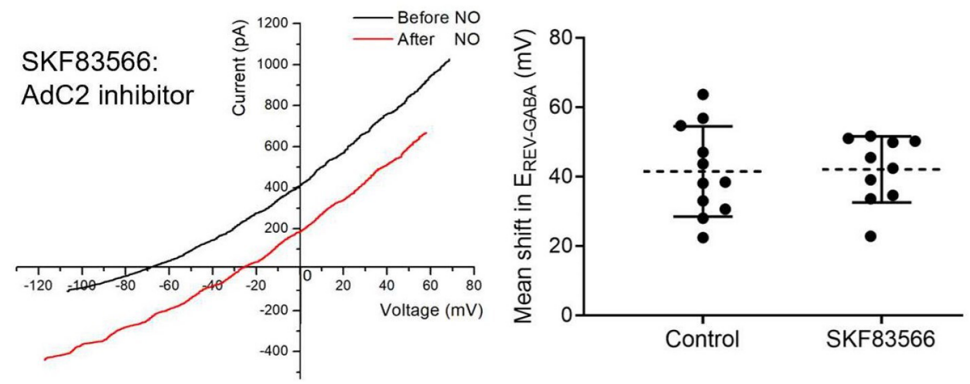

$\mathrm{H}$
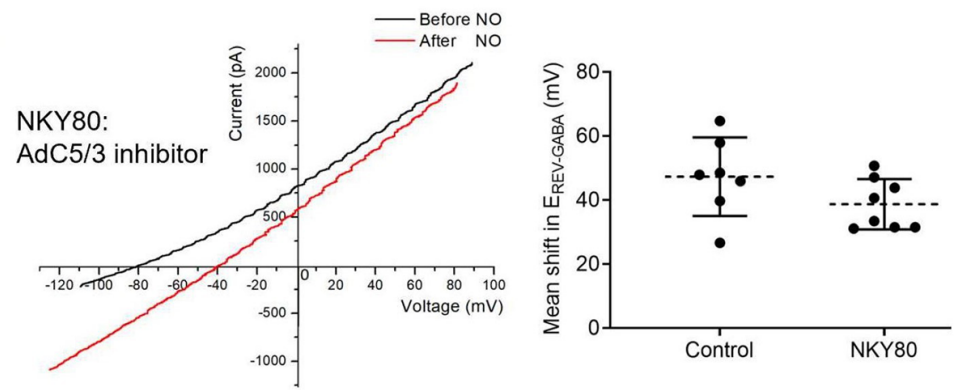

FIGURE 3 | AdC1 inhibitors suppress NO-dependent $\mathrm{Cl}^{-}$release. (A) Data from cells recorded under control condition (left) or pre-incubated with general AdC inhibitor, SQ22536 (100 nM) for 30 min (right) showing reduced shift amplitudes. (B) The quantified mean shift in $E_{\text {REV-GABA }} \pm$ SEM; $n=11$ each. ${ }^{\star \star \star \star} P<0.0001$ (unpaired $t$-test). (C) Pre-incubation with AdC 1 inhibitor, ST034307 (100 nM) for 30 min, suppresses the NO-dependent shift in $E_{R E V-G A B A}$. (D) The quantified mean shift in $E_{\text {REV-GABA }} \pm$ SEM; $n=9$. ${ }^{\star \star *} P<0.001$ (unpaired $t$-test). (E) Pre-incubation with the AdC 2 inhibitor, SKF83566 (10 $\mu$ M) for 20 min, does not inhibit the NO-dependent shift in EREV-GABA. (F) The quantified mean shift in $E_{\mathrm{REV}-\mathrm{GABA}} \pm \mathrm{SEM}$; control, $n=11$; SKF83566, $n=10$. $P=0.91$ (unpaired $t$-test). (G) Pre-incubation with the AdC 5/3 inhibitor, NKY80 (200 $\mu$ M) for 20 min does not block the NO-dependent shift. (H) The quantified mean shift in EREV-GABA \pm SEM; control, $n=7$; $\mathrm{NKY80}, n=8 . P=0.13$ (unpaired $t$-test).

test, Figures $\mathbf{8 A}, \mathbf{B}, \mathbf{D})$. Either store release of $\mathrm{Ca}^{2+}$ or elevation of cAMP was less effective than $\mathrm{NO}$ in eliciting release of internal $\mathrm{Cl}^{-}$(Figures 5B,C; 8B,D). As such, we hypothesized that releasing stored $\mathrm{Ca}^{2+}$ and the downstream effects of elevating cytosolic cAMP would have synergistic effects on $\mathrm{Cl}^{-}$release. To test this, ionomycin and cAMP ct were co-applied and the effect on GABA-gated currents in zero $\mathrm{Ca}^{2+}$ external and zero $\mathrm{Cl}^{-}$internal and external solutions was determined under 
A
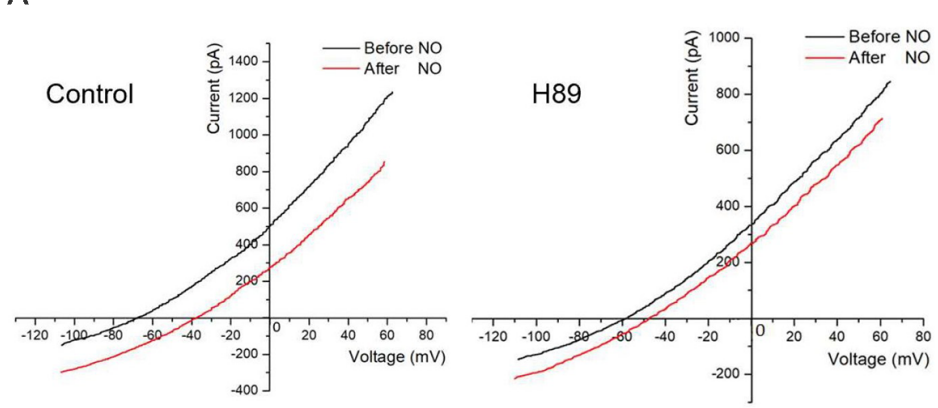

B

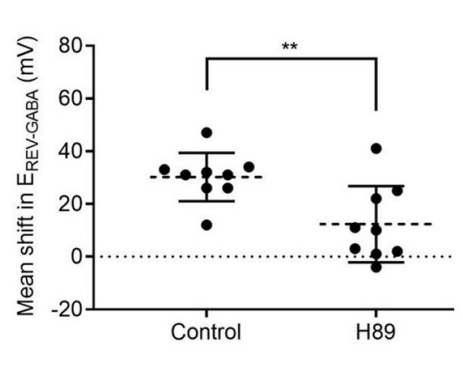

C
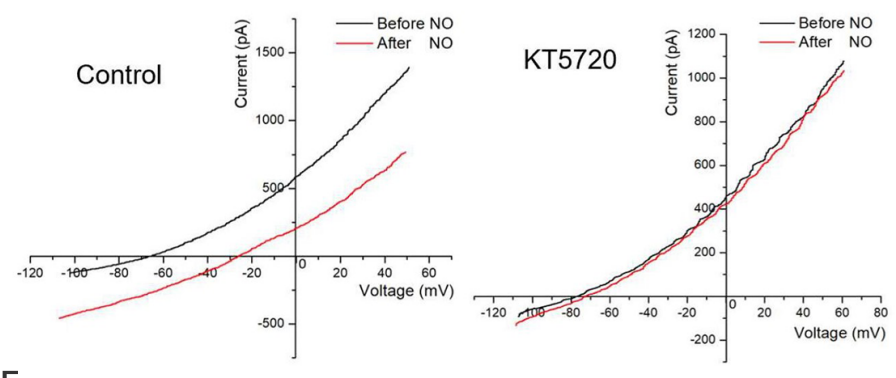

D

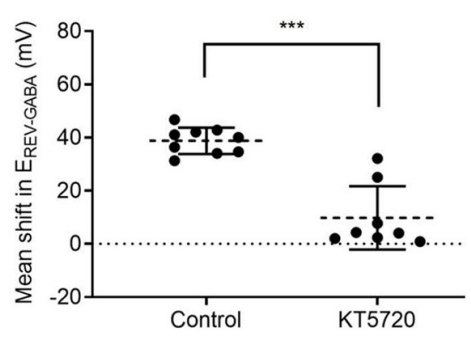

E

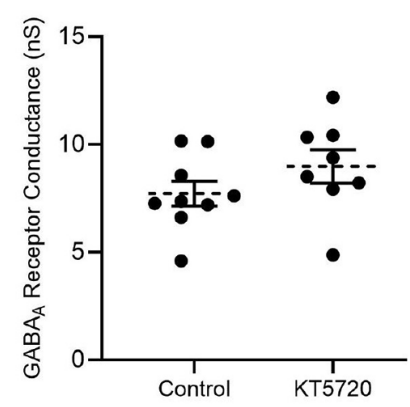

FIGURE 4 | PKA activity is required for the NO-dependent shift in EREV-GABA. (A) Date from cells recorded under control condition (left) or pre-incubated with a kinase inhibitor, H89 $(1 \mu \mathrm{M})$ for $30 \mathrm{~min}$ (right) that suppresses the NO-dependent shift in $E_{\text {REV-GABA. }}$ (B) The quantified mean shift in $E_{\text {REV-GABA }} \pm \mathrm{SEM} ; n=9$.

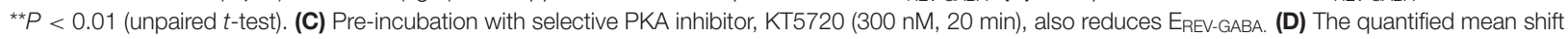
$E_{\text {REV-GABA }} \pm$ SEM; control, $n=9$; KT5720, $n=8 .{ }^{* * *} P<0.001$ (Welch's unpaired $t$-test). (E) The quantified mean GABA $A_{A}$ receptor conductance \pm SEM; control, $n=9 ; \mathrm{KT} 5720, n=8 . P=0.2057$ (unpaired $t$-test).

these conditions, the effects of $\mathrm{NO}$ could be mimicked (NO, $-13.1 \pm 2.6 \mathrm{pA}, n=13 ;$ cAMP ct + ionomycin, $-9.0 \pm 0.8 \mathrm{pA}$, $n=14 ; p=0.1588$, Welch's unpaired $t$-test, Figures 8 C,D). Together, these results provide evidence that $\mathrm{Ca}^{2+}$-dependent AdC1 provides a link between NO-dependent cytosolic $\mathrm{Ca}^{2+}$ signaling and cytosolic $\mathrm{Cl}^{-}$concentration.

\section{DISCUSSION}

Here we show that by eliciting $\mathrm{Ca}^{2+}$ release, NO sets the conditions for CFTR-dependent efflux of $\mathrm{Cl}^{-}$from internal stores. We establish that $\mathrm{Ca}^{2+}$ store release, AdCl activation, and PKA activation are all necessary for the NO-dependent release of $\mathrm{Cl}^{-}$into the cytosol. Our attempts to bypass $\mathrm{NO}$ and the $\mathrm{Ca}^{2+}$ elevations by experimentally elevating cytosolic cAMP engendered $\mathrm{Cl}^{-}$release, but these manipulations were not as effective as NO itself. Combining cAMP elevations with the release of stored $\mathrm{Ca}^{2+}$ generated $\mathrm{Cl}^{-}$release indistinguishable from NO. This implies that there might be an additional $\mathrm{Ca}^{2+}$-dependent component to this mechanism that is as yet, unidentified. Taken together, these results establish that AdC1 links calcium signaling and the cAMP pathway to the regulation of cytosolic $\mathrm{Cl}^{-}$via CFTR.

\section{CFTR and CAMP Signaling Interactions}

It is well established that activation of CFTR is modulated by the cAMP signaling pathway (Anderson and Welsh, 1991). Here we report that AdC1, specifically, is a site of interaction between 
A

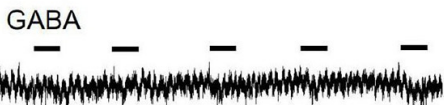

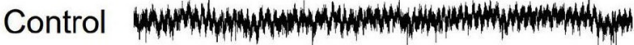

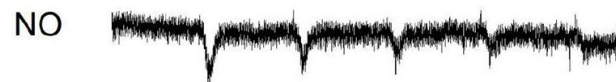

C

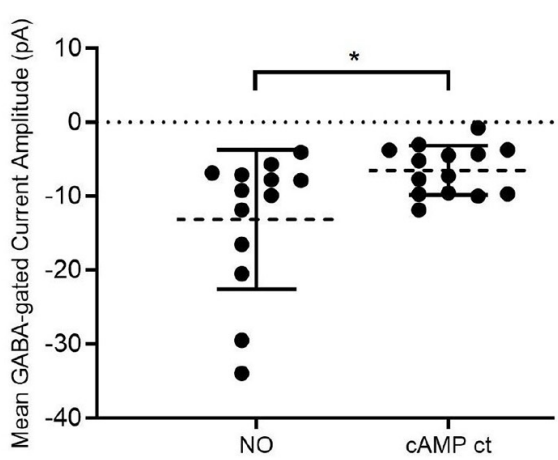

B

Control GABA

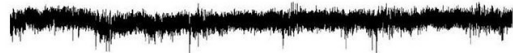

cAMP ct

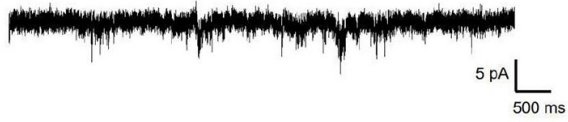

FIGURE 5 | Elevating CAMP in the absence of NO promotes $\mathrm{Cl}^{-}$release from the internal store. (A) Sample traces from cells are held at $-70 \mathrm{mV}$ with $\mathrm{GABA}$ (20 $\mu \mathrm{M}$ ) applied for $400 \mathrm{~ms}$. In the presence of NO, a GABA-gated inward current appears indicating that $\mathrm{Cl}^{-}$had been released into the cytosol. (B) In different cells, exposure to a cocktail of reagents selected to elevate cAMP (cAMP ct: forskolin, $1 \mu \mathrm{M}$; 8-bromo-cAMP, $100 \mu \mathrm{M}$; IBMX, $20 \mu \mathrm{M}$ ) but no NO, results in a small GABA-dependent inward current. (C) The quantified mean GABA-gated current amplitude \pm SEM; NO, $n=13$; cocktail, $n=14$. ${ }^{*} P<0.05$ (Welch's unpaired $t$-test).

A

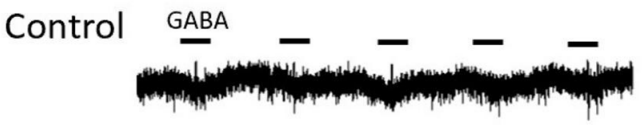

NO

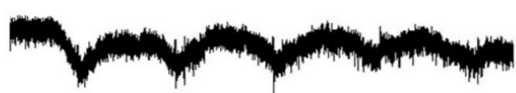

C

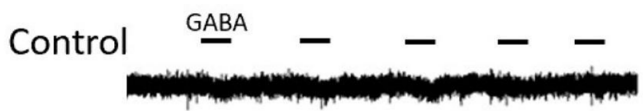

After V-S

$\left(\mathrm{Ca}^{2+}\right)$

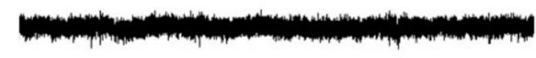

B

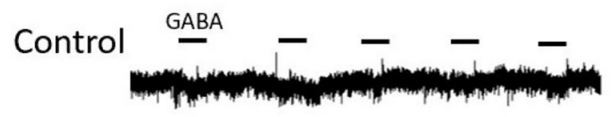

After $\mathrm{V}-\mathrm{S}$

$\left(0 \mathrm{Ca}^{2+}\right)$

$15 \mathrm{pA} \underset{500 \mathrm{~ms}}{\longleftarrow}$

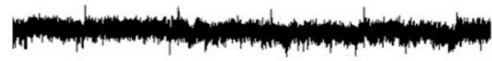

D

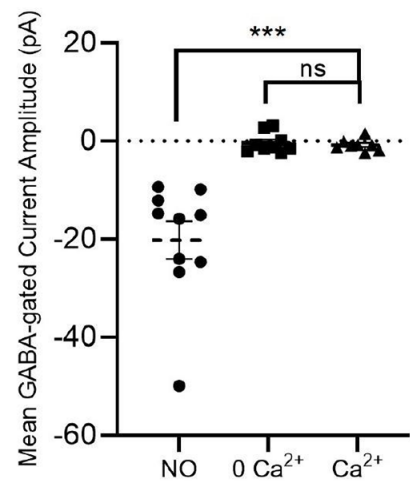

FIGURE 6 | Influx of external $\mathrm{Ca}^{2+}$ fails to release $\mathrm{Cl}^{-}$from the internal store. (A) Sample traces from cells are held at $-70 \mathrm{mV}$ with $\mathrm{GABA}$ (20 $\left.\mu \mathrm{M}\right)$ applied for 400 ms. With NO stimulation, GABA-gated inward currents generate. (B) Voltage-step control settings in zero $\mathrm{Ca}^{2+}$ zero $\mathrm{Cl}^{-}$external environment. Sample traces from cells that the top trace is stimulated with GABA pulse protocol, the bottom trace is repeated with GABA pulse protocol after voltage step stimulation. (C) Same experiment setting in $\mathrm{Ca}^{2+}(3 \mathrm{mM})$ external solution. (D) The quantified mean GABA-gated current amplitude $\pm \mathrm{SEM}$; NO control, $n=10 ; 0 \mathrm{Ca}{ }^{2+}$ control, $n=9$; $\mathrm{Ca}^{2+}, n=8 ; p=0.6$; ns: not significant. ${ }^{\star \star \star} P<0.001$ (repeated-measures ANOVA). 
A

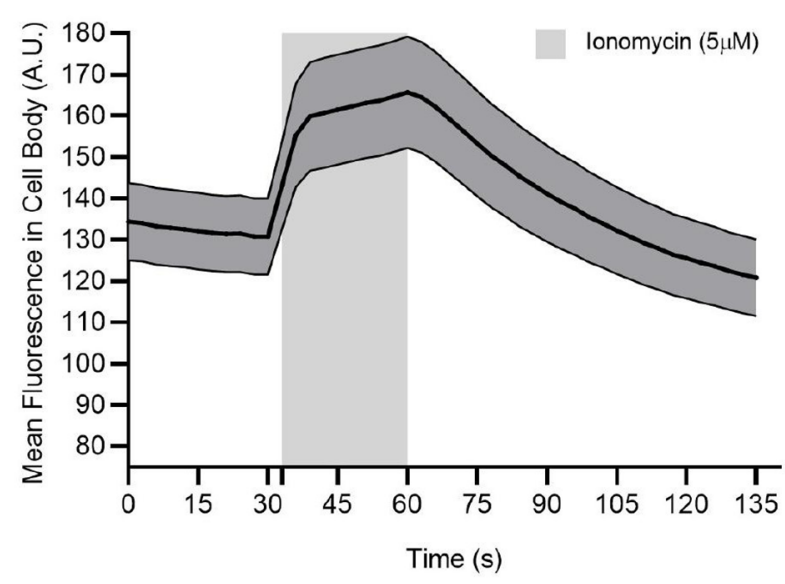

C

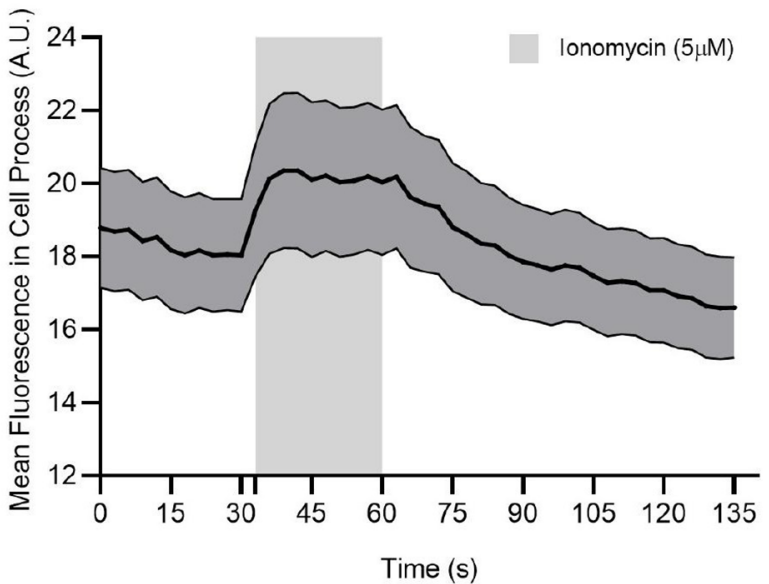

B

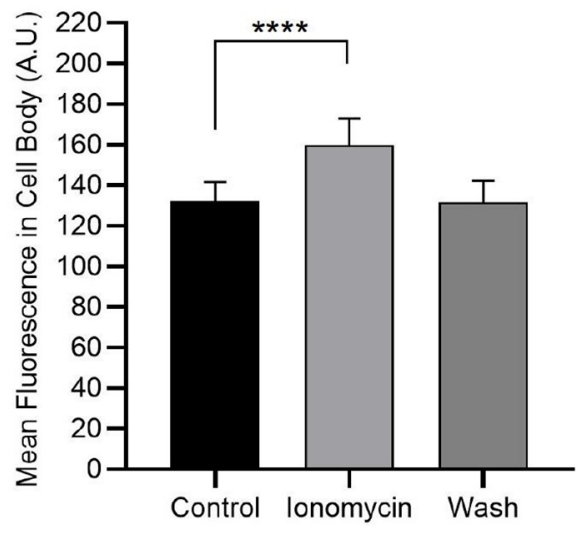

D

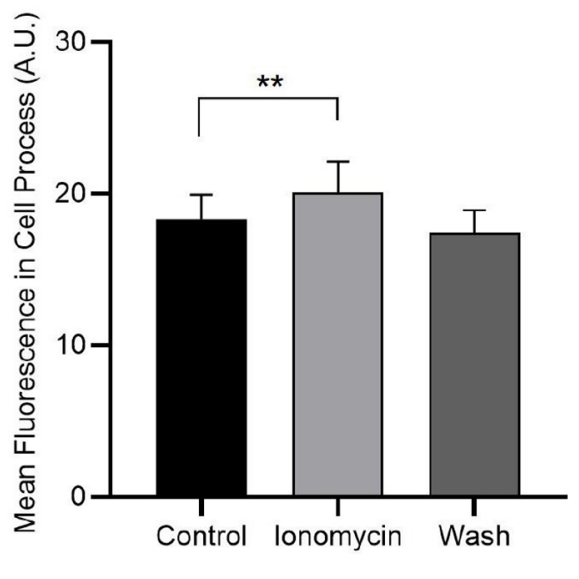

FIGURE 7 | In the absence of extracellular $\mathrm{Ca}^{2+}$, ionomycin releases $\mathrm{Ca}^{2+}$ from internal stores. Calcium imaging experiments of $\mathrm{AC}$ cell body and cell process are loaded with Oregon Green BAPTA-1 488-AM. (A) lonomycin (5 $\mu \mathrm{M})$ increases cytosolic $\mathrm{Ca}^{2+}$ in the cell body. (B) The quantified mean fluorescence \pm SEM; $n=73$. ${ }^{\star \star \star \star} P<0.0001$ (paired $t$-test). (C) lonomycin $(5 \mu \mathrm{M})$ increases cytosolic $\mathrm{Ca}^{2+}$ in the cell process. (D) The quantified mean fluorescence \pm SEM; $n=58 .{ }^{\star \star} P<0.01$ (paired $t$-test).

$\mathrm{Ca}^{2+}$ and cAMP for CFTR regulation in chick ACs. Functional coupling between AdC1 and CFTR has been demonstrated in human bronchial cell lines (Namkung et al., 2010; Lérias et al., 2018) airway, and intestinal epithelia (Benedetto et al., 2017) and human fetal lung explants (Brennan et al., 2016). Here, we demonstrate for the first time, a similar relationship in neurons.

A common theme for CFTR is that it forms function partnerships with other transport proteins (Li and Naren, 2010). It has become well established in epithelial cells that a physical and functional relationship exists between CFTR and TMEM16A (anoctamin 1), a Ca ${ }^{2+}$-activated $\mathrm{Cl}^{-}$channel (Ousingsawat et al., 2011; Benedetto et al., 2017, 2019). Interestingly, TMEM16A has been localized to AC-AC GABAergic synapses in the mouse retina (Jeon et al., 2013) and we have evidence that it is expressed in cultured GABAergic chick ACs at the mRNA and protein levels (unpublished observations). Two emerging properties of TMEM16A make it a good candidate for an additional $\mathrm{Ca}^{2+}$-dependent component of the CFTR activation mechanism in ACs. First, in epithelia, the co-expression of TMEM16A and CFTR confers a system where cytosolic $\mathrm{Ca}^{2+}$ elevations and activation of the cAMP pathway become intertwined by the activity of $\mathrm{Ca}^{2+}$-dependent AdCs, mostly likely AdC1 (Benedetto et al., 2017; Lérias et al., 2018). Furthermore, although the mechanism is not understood, expression of TMEM16A enhances $\mathrm{G}$-protein coupled receptor-mediated $\mathrm{Ca}^{2+}$ release via inositol 1,4,5-trisphosphate receptors ( $\mathrm{IP}_{3} \mathrm{R}$; Schreiber et al., 2015; Benedetto et al., 2017). It may be that TMEM16A serves 


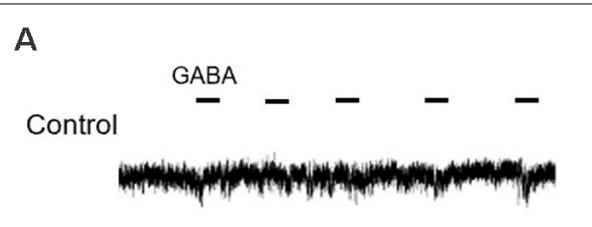

NO

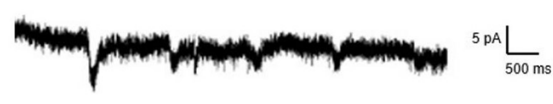

B

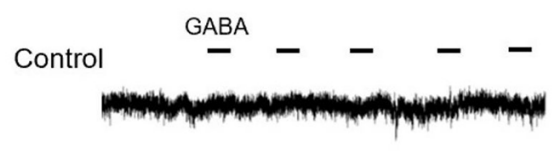

Ionomycin $(5 \mu \mathrm{M})$
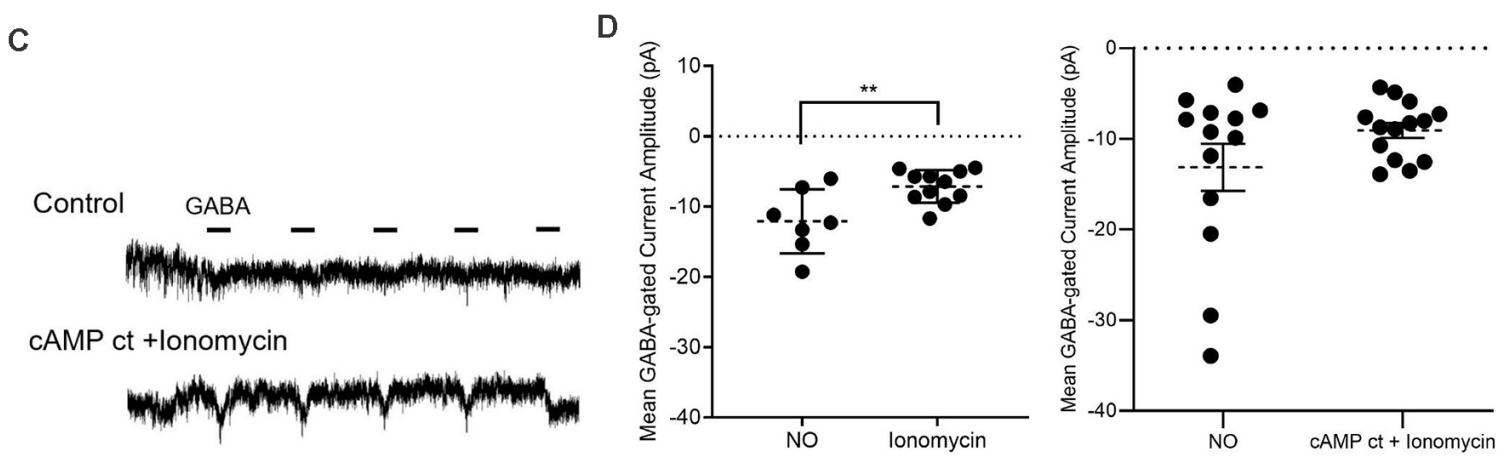

FIGURE 8 | Pairing elevated cAMP and $\mathrm{Ca}^{2+}$ mimics the effects of NO. (A-C) Sample traces from GABA pulse recording (20 $\left.\mu \mathrm{M}\right)$ in zero external $\mathrm{Ca}^{2+}$ and zero $\mathrm{Cl}^{-}$ internal and external solutions. The GABA-dependent inward current is elicited by $\mathrm{NO}(50 \mu \mathrm{l})$ in (A) by $\mathrm{Ca}^{2+}$ ionophore, ionomycin $(5 \mu \mathrm{M})$ in (B), and by co-application of cAMP ct and ionomycin (5 $\mu \mathrm{M})$ in (C). (D) The quantified mean GABA-gated current amplitude \pm SEM; NO, $n=7$; ionomycin, $n=11$. NO, $n=13$ (control cells are replotted from Figure 5D, see "Materials and Methods" section); cAMP ct and ionomycin, $n=14$. ${ }^{\star \star} P<0.01$ (left: unpaired $t$-test, right: Welch's unpaired $t$-test).

a similar function in ACs, even in the absence of receptor activation. Second, it has been elegantly demonstrated that TMEM16A is activated by $\mathrm{Ca}^{2+}$ released from stores exclusively, in epithelia (Cabrita et al., 2017) and sensory neurons (Jin et al., 2013). These reports align with our observation that only store-released $\mathrm{Ca}^{2+}$ is effective in eliciting elevations in cytosolic $\mathrm{Cl}^{-}$.

\section{$\mathrm{Ca}^{2+}$ Signaling for $\mathrm{Cl}^{-}$Regulation}

We find that $\mathrm{Ca}^{2+}$ influx is not effective in enhancing cytosolic $\mathrm{Cl}^{-}$but that $\mathrm{Ca}^{2+}$ store release is. AdC1 is typically expressed on the plasma membrane as are voltage-gated $\mathrm{Ca}^{2+}$ channels, so our observations suggest that the expression of these two membrane proteins is significantly non-overlapping. Furthermore, the effectiveness of $\mathrm{Ca}^{2+}$ store release raises the possibility that the $\mathrm{Ca}^{2+}$ store release mechanism is localized together with $\mathrm{Cl}^{-}$ release sites.

The mechanism by which $\mathrm{NO}$ releases internal $\mathrm{Ca}^{2+}$ in $\mathrm{ACs}$ remains unknown. We have previously determined that the effect of $\mathrm{NO}$ on cytosolic $\mathrm{Cl}^{-}$in ACs is independent of soluble guanylyl cyclase activity (Hoffpauir et al., 2006). This observation raises the possibility that NO functions via S-nitrosylation. NO can activate ryanodine receptors (RyRs) via S-nitrosylation (Eu et al., 2000), and NO-dependent release of store $\mathrm{Ca}^{2+}$ via $\mathrm{RyRs}$ was shown to affect cerebellar neuron synaptic plasticity as well as cell death (Kakizawa et al., 2012). In addition, the $\mathrm{IP}_{3} \mathrm{R}$ can be $\mathrm{S}$-nitrosylated and elicit $\mathrm{Ca}^{2+}$ release from the $\mathrm{IP}_{3}$-sensitive store in human neutrophils (Pan et al., 2008). The interplay between $\mathrm{IP}_{3} \mathrm{R}$ and $\mathrm{RyR}$ has been demonstrated in the production of cytosolic $\mathrm{Ca}^{2+}$ waves (Boittin et al., 1999; Gordienko and Bolton, 2002), and both receptors are expressed in cultured ACs (Warrier et al., 2005; Sen et al., 2007).

Acidic organelles such as lysosomes (Patel and Docampo, 2010) are another potential source of $\mathrm{Ca}^{2+}$. This $\mathrm{Ca}^{2+}$ store can be mobilized in response to nicotic acid adenine dinucleotide phosphate (NAADP) activation of $\mathrm{Ca}^{2+}$ permeable two-pore channels (TPCs; Calcraft et al., 2009). However, the only link between NO and the pathway we have identified is that cAMP can regulate NAADP production (Wilson and Galione, 1998). Nonetheless, it is an intriguing possibility that acidic organelles might function in both mobilizing $\mathrm{Ca}^{2+}$ and regulating $\mathrm{Cl}^{-}$levels in the cytosol.

Can signaling molecules other than NO link cytosolic $\mathrm{Ca}^{2+}$ and cytosolic $\mathrm{Cl}^{-}$? Chick ACs have been demonstrated to express neurotensin receptors that are coupled to $\mathrm{Ca}^{2+}$ store release via Gq-activated phospholipase C and $\mathrm{IP}_{3}$ Rs (Borges et al., 1996). Neurotensin itself is expressed by a population of adult chicken ACs that co-express both enkephalin and somatostatin (Watt and Florack, 1994). Interestingly, the levels of all three peptides exhibit light-dependent oscillations in release with the highest level of release occurring in the dark (Yang et al., 1997). Thus, if neurotensin acting on its receptor can link $\mathrm{Ca}^{2+}$ elevations with $\mathrm{Cl}^{-}$elevations, we would expect this effect to be most robust under scotopic conditions.

The metabotropic glutamate receptor mGluR5 has also been demonstrated to be linked to the $\mathrm{IP}_{3}$ pathway in chick ACs (Sosa et al., 2002; Sosa and Gleason, 2004). In addition, mGluR5 has been localized to ACs in the adult chicken retina 
at the light microscope level (Kreimborg et al., 2001) and in AC processes in the electron microscope (Sen and Gleason, 2006). Dopamine is a key retinal regulator in the vertebrate retina and D1 (AdC-linked) dopamine receptors are expressed in the inner retina across vertebrates (Veruki and Wässle, 1996; Mora-Ferrer et al., 1999; as reviewed in Nguyen-Legros et al., 1999) including the chicken retina (Firth et al., 1997). Although D1 receptors are linked to elevations in cAMP, it may be that their effect on cytosolic $\mathrm{Cl}^{-}$is relatively small given the limited effects we found for the cAMP cocktail in our experiments. Nonetheless, it remains possible that NO is not the only signaling molecule with the potential to regulate cytosolic $\mathrm{Cl}^{-}$. However, given what we have learned about the importance of the $\mathrm{Ca}^{2+}$ source, the location of these receptors is likely to be a significant determining factor in their involvement.

Wexler et al. (1998) tested the NO donor SNAP on cultured rat ACs and found that downstream suppression of PKA activity reduced GABA receptor-mediated current. With similar concentrations of SNAP, we have previously demonstrated a small $(\sim 15 \%)$ enhancement in the GABA-gated current but no shift in $E_{\text {REV-GABA }}$ (Hoffpauir et al., 2006). In the present experiments, we see no effect of PKA inhibition on the conductance of the GABA response. In Wexler et al. (1998), PKA activity was modified acutely and effects began to diminish within a few minutes during reagent application and at a rate that would have brought the effect back to baseline in about $10 \mathrm{~min}$. Our PKA inhibitor experiments involved $20 \mathrm{~min}$ pre-incubations such that any acute effects could have been reversed by the time we made our recordings. Alternatively, in addition to potential species differences, ACs are a diverse group, and differences in timing and preparation, and maintenance of cultures could easily select for a different sub-population of ACs.

Nitric oxide synthases (NOS) are widespread in the chicken retina (Tekmen-Clark and Gleason, 2013) and there are four

\section{REFERENCES}

Anderson, M. P., and Welsh, M. J. (1991). Calcium and cAMP activate different chloride channels in the apical membrane of normal and cystic fibrosis epithelia. Proc. Natl. Acad. Sci. U S A 88, 6003-6007. doi: 10.1073/pnas.88. 14.6003

Ben-Ari, Y., Khalilov, I., Kahle, K. T., and Cherubini, E. (2012). The GABA excitatory/inhibitory shift in brain maturation and neurological disorders. Neuroscientist 18, 467-486. doi: 10.1177/10738584 12438697

Benedetto, R., Cabrita, I., Schreiber, R., and Kunzelmann, K. (2019). TMEM16A is indispensable for basal mucus secretion in airways and intestine. FASEB J. 33, 4502-4512. doi: 10.1096/fj.201801333RRR

Benedetto, R., Ousingsawat, J., Wanitchakool, P., Zhang, Y., Holtzman, M. J., Amaral, M., et al. (2017). Epithelial chloride transport by CFTR requires TMEM16A. Sci. Rep. 7:12397. doi: 10.1038/s41598-017-10910-0

Billet, A., and Hanrahan, J. W. (2013). The secret life of CFTR as a calciumactivated chloride channel. J. Physiol. 591, 5273-5278. doi: 10.1113/jphysiol. 2013.261909

Boittin, F. X., Macrez, N., Halet, G., and Mironneau, J. (1999). Norepinephrineinduced $\mathrm{Ca} 2+$ waves depend on InsP3 and ryanodine receptor activation in vascular myocytes. Am. J. Physiol. 277, C139-C151. doi: 10.1152/ajpcell.1999. 277.1.C139 subtypes of chick ACs expressed neuronal NOS (nNOS), specifically (Fischer and Stell, 1999). Furthermore, it has been reported that nNOS expression is clustered in the presynaptic region of some ACs dendrites (Cao and Eldred, 2001) and NO imaging shows that diffusion from AC processes is limited (Eldred and Blute, 2005). Together, these observations suggest that although $\mathrm{NO}$ can be generated broadly in the retina, its effects could be highly localized to pre-and post-synaptic partners in the inner retina. As we develop a deeper understanding of the signaling mechanisms underlying NOand CFTR-dependent cytosolic $\mathrm{Cl}^{-}$regulation, we may uncover additional regulators of inhibition that play a role in AC synaptic output and thus the signals that retina ganglion cells convey to visual centers in the brain.

\section{DATA AVAILABILITY STATEMENT}

The raw data supporting the conclusions of this article will be made available by the authors, without undue reservation.

\section{ETHICS STATEMENT}

The animal study was reviewed and found to be exempt by the LSU Institutional Animal Care and Use Committee.

\section{AUTHOR CONTRIBUTIONS}

LZ and EG planned the experiments and drafted the manuscript. LZ carried out all of the experiments. All authors contributed to the article and approved the submitted version.

\section{ACKNOWLEDGMENTS}

We thank Dr. Huangen Ding and his lab for generously supplying us with NO-bubbled solutions.

Borges, S., Gleason, E., Frerking, M., and Wilson, M. (1996). Neurotensin induces calcium oscillations in cultured amacrine cells. Vis. Neurosci. 13, 311-318. doi: 10.1017/s0952523800007550

Bozoky, Z., Ahmadi, S., Milman, T., Kim, T. H., Du, K., Di Paola, M., et al. (2017). Synergy of cAMP and calcium signaling pathways in CFTR regulation. Proc. Natl. Acad. Sci. U S A 114, E2086-E2095. doi: 10.1073/pnas.1613 546114

Brennan, S. C., Wilkinson, W. J., Tseng, H. -E., Finney, B., Monk, B., Dibble, H., et al. (2016). The extracellular calcium-sensing receptor regulates human fetal lung development via CFTR. Sci. Rep. 6:21975. doi: 10.1038/srep21975

Cabrita, I., Benedetto, R., Fonseca, A., Wanitchakool, P., Sirianant, L., Skryabin, B. V., et al. (2017). Differential effects of anoctamins on intracellular calcium signals. FASEB J. 31, 2123-2134. doi: 10.1096/fj. 201600797RR

Calcraft, P. J., Ruas, M., Pan, Z., Cheng, X., Arredouani, A., Hao, X., et al. (2009). NAADP mobilizes calcium from acidic organelles through two-pore channels. Nature 459, 596-600. doi: 10.1038/nature08030

Cao, L., and Eldred, W. D. (2001). Subcellular localization of neuronal nitric oxide synthase in turtle retina: electron immunocytochemistry. Vis. Neurosci. 18 , 949-960. doi: 10.1017/S0952523801186128

Choi, E. J., Xia, Z., and Storm, D. R. (1992). Stimulation of the type III olfactory adenylyl cyclase by calcium and calmodulin. Biochemistry 31, 6492-6498. doi: $10.1021 /$ bi00143a019 
Delpire, E., and Mount, D. B. (2002). Human and murine phenotypes associated with defects in cation-chloride cotransport. Annu. Rev. Physiol. 64, 803-843. doi: 10.1146/annurev.physiol.64.081501.155847

Diamond, J. S. (2017). Inhibitory interneurons in the retina: types, circuitry and function. Annu. Rev. Vis. Sci. 3, 1-24. doi: 10.1146/annurev-vision-102016061345

Eldred, W. D., and Blute, T. A. (2005). Imaging of nitric oxide in the retina. Vis. Res. 45, 3469-3486. doi: 10.1016/j.visres.2005.07.033

Eu, J. P., Sun, J., Xu, L., Stamler, J. S., and Meissner, G. (2000). The skeletal muscle calcium release channel: coupled $\mathrm{O} 2$ sensor and NO signaling functions. Cell 102, 499-509. doi: 10.1016/s0092-8674(00)00054-4

Feigenspan, A., and Bormann, J. (1994). Facilitation of GABAergic signaling in the retina by receptors stimulating adenylate cyclase. Proc. Natl. Acad. Sci. U S A 91, 10893-10897. doi: 10.1073/pnas.91.23.10893

Firth, S. I., Morgan, I. G., and Boelen, M. K. (1997). Localization of D1 dopamine receptors in the chicken retina. Aust. N. Z. J. Ophthalmol. 25, S64-S66. doi: 10.1111/j.1442-9071.1997.tb01760.x

Fischer, A. J., and Stell, W. K. (1999). Nitric oxide synthase-containing cells in the retina, pigmented epithelium, choroid and sclera of the chick eye. J. Comp. Neurol. 405, 1-14. doi: 10.1002/(sici)1096-9861(19990301)405:1<1::aidcne1>3.0.co; $2-\mathrm{u}$

Gadsby, D. C., and Nairn, A. C. (1999). Control of CFTR channel gating by phosphorylation and nucleotide hydrolysis. Physiol. Rev. 79, S77-S107. doi: 10.1152/physrev.1999.79.1.S77

Gamba, G. (2005). Molecular physiology and pathophysiology of electroneutral cation-chloride cotransporters. Physiol. Rev. 85, 423-493. doi: 10.1152/physrev. 00011.2004

Gleason, E., Borges, S., and Wilson, M. (1993). Synaptic transmission between pairs of retinal amacrine cells in culture. J. Neurosci. 13, 2359-2370. doi: 10.1523/JNEUROSCI.13-06-02359.1993

Gordienko, D. V., and Bolton, T. B. (2002). Crosstalk between ryanodine receptors and IP3 receptors as a factor shaping spontaneous Ca2+-release events in rabbit portal vein myocytes. J. Physiol. 542, 743-762. doi: 10.1113/jphysiol. 2001.015966

Grimes, W. N. (2012). Amacrine cell-mediated input to bipolar cells: variations on a common mechanistic theme. Vis. Neurosci. 29, 41-49. doi: 10.1017/S0952523811000241

Halls, M. L., and Cooper, D. M. (2011). Regulation by Ca2+-signaling pathways of adenylyl cyclases. Cold Spring Harb. Perspect. Biol. 3:a004143. doi: 10.1101/cshperspect.a004143

Hoffpauir, B., McMains, E., and Gleason, E. (2006). Nitric oxide transiently converts synaptic inhibition to excitation in retinal amacrine cells. J. Neurophysiol. 95, 2866-2877. doi: 10.1152/jn.01317.2005

Jeon, J. H., Paik, S. S., Chun, M. -H., Oh, U., and Kim, I. -B. (2013). Presynaptic localization and possible function of calcium-activated chloride channel anoctamin 1 in the mammalian retina. PLoS One 8:e67989. doi: 10.1371/journal.pone.0067989

Jin, X., Shah, S., Liu, Y., Zhang, H., Lees, M., Fu, Z., et al. (2013). Activation of the $\mathrm{Cl}-$ channel ANO1 by localized calcium signals in nociceptive sensory neurons requires coupling with the IP3 receptor. Sci. Signal. 6:ra73. doi: 10.1126/scisignal.2004184

Kakizawa, S., Yamazawa, T., Chen, Y., Ito, A., Murayama, T., Oyamada, H., et al. (2012). Nitric oxide-induced calcium release via ryanodine receptors regulates neuronal function. EMBO J. 31, 417-428. doi: 10.1038/emboj.2011.386

Kreimborg, K. M., Lester, M. L., Medler, K. F., and Gleason, E. L. (2001). Group I metabotropic glutamate receptors are expressed in the chicken retina and by cultured retinal amacrine cells. J. Neurochem. 77, 452-465. doi: 10.1046/j.14714159.2001.00225.x

Krishnan, V., and Gleason, E. (2015). Nitric oxide releases Cl- from acidic organelles in retinal amacrine cells. Front. Cell. Neurosci. 9:213. doi: 10.3389/fncel.2015.00213

Krishnan, V., Maddox, J. W., Rodriguez, T., and Gleason, E. (2017). A role for the cystic fibrosis transmembrane conductance regulator in the nitric oxide-dependent release of $\mathrm{Cl}-$ from acidic organelles in amacrine cells. J. Neurophysiol. 118, 2842-2852. doi: 10.1152/jn.00511.2017

Kunzelmann, K., and Mehta, A. (2013). CFTR: a hub for kinases and crosstalk of cAMP and Ca2+. FEBS J. 280, 4417-4429. doi: 10.1111/febs.12457

Lérias, J., Pinto, M., Benedetto, R., Schreiber, R., Amaral, M., Aureli, M., et al. (2018). Compartmentalized crosstalk of CFTR and TMEM16A (ANO1) through EPAC1 and ADCY1. Cell. Signal. 44, 10-19. doi: 10.1016/j.cellsig.2018. 01.008

Li, C., and Naren, A. P. (2010). CFTR chloride channel in the apical compartments: spatiotemporal coupling to its interacting partners. Integr. Biol. (Camb) 2, 161-177. doi: 10.1039/b924455g

MacNeil, M. A., and Masland, R. H. (1998). Extreme diversity among amacrine cells: implications for function. Neuron 20, 971-982. doi: 10.1016/s08966273(00)80478-x

Maddox, J. W., and Gleason, E. (2017). Nitric oxide promotes GABA release by activating a voltage-independent $\mathrm{Ca} 2+$ influx pathway in retinal amacrine cells. J. Neurophysiol. 117, 1185-1199. doi: 10.1152/jn.00803.2016

Maddox, J. W., Khorsandi, N., and Gleason, E. (2018). TRPC5 is required for the NO-dependent increase in dendritic $\mathrm{Ca} 2+$ and GABA release from chick retinal amacrine cells. J. Neurophysiol. 119, 262-273. doi: 10.1152/jn.00500.2017

Masada, N., Ciruela, A., MacDougall, D. A., and Cooper, D. M. (2009). Distinct mechanisms of regulation by Ca2+/calmodulin of type 1 and 8 adenylyl cyclases support their different physiological roles. J. Biol. Chem. 284, 4451-4463. doi: 10.1074/jbc.M807359200

Mons, N., Yoshimura, M., and Cooper, D. M. (1993). Discrete expression of $\mathrm{Ca} 2+/$ calmodulin-sensitive and $\mathrm{Ca} 2+$-insensitive adenylyl cyclases in the rat brain. Synapse 14, 51-59. doi: 10.1002/syn.890140108

Mora-Ferrer, C., Yazulla, S., Studholme, K. M., and Haak-Frendscho, M. (1999). Dopamine D1-receptor immunolocalization in goldfish retina. J. Comp. Neurol. 411, 705-714. doi: 10.1002/(sici)1096-9861(19990906)411:4<705::aid-cne14>3. $0 . \operatorname{co} ; 2-y$

Namkung, W., Finkbeiner, W. E., and Verkman, A. S. (2010). CFTRadenylyl cyclase I association responsible for UTP activation of CFTR in well-differentiated primary human bronchial cell cultures. Mol. Biol. Cell. 21, 2639-2648. doi: 10.1091/mbc.E09-12-1004

Nguyen-Legros, J., Versaux-Botteri, C., and Vernier, P. (1999). Dopamine receptor localization in the mammalian retina. Mol. Neurobiol. 19, 181-204. doi: $10.1007 / \mathrm{BF} 02821713$

Ousingsawat, J., Kongsuphol, P., Schreiber, R., and Kunzelmann, K. (2011). CFTR and TMEM16A are separate but functionally related Cl-channels. Cell. Physiol. Biochem. 28, 715-724. doi: 10.1159/000335765

Pan, L., Zhang, X., Song, K., Wu, X., and Xu, J. (2008). Exogenous nitric oxideinduced release of calcium from intracellular IP3 receptor-sensitive stores via S-nitrosylation in respiratory burst-dependent neutrophils. Biochem. Biophys. Res. Commun. 377, 1320-1325. doi: 10.1016/j.bbrc.2008.11.001

Patel, S., and Docampo, R. (2010). Acidic calcium stores open for business: expanding the potential for intracellular Ca2+ signaling. Trends Cell Biol. 20, 277-286. doi: 10.1016/j.tcb.2010.02.003

Payne, J. A., Rivera, C., Voipio, J., and Kaila, K. (2003). Cation-chloride co-transporters in neuronal communication, development and trauma. Trends Neurosci. 26, 199-206. doi: 10.1016/S0166-2236(03)00068-7

Picciotto, M., Cohn, J., Bertuzzi, G., Greengard, P., and Nairn, A. (1992). Phosphorylation of the cystic fibrosis transmembrane conductance regulator. J. Biol. Chem. 267, 12742-12752.

Porter, N. M., Twyman, R. E., Uhler, M. D., and Macdonald, R. L. (1990). Cyclic AMP-dependent protein kinase decreases GABAA receptor current in mouse spinal neurons. Neuron 5, 789-796. doi: 10.1016/0896-6273(90)90338-g

Quinton, P. M. (1999). Physiological basis of cystic fibrosis: a historical perspective. Physiol. Rev. 79, S3-S22. doi: 10.1152/physrev.1999.79.1.S3

Quinton, P. M., and Bijman, J. (1983). Higher bioelectric potentials due to decreased chloride absorption in the sweat glands of patients with cystic fibrosis. N. Engl. J. Med. 308, 1185-1189. doi: 10.1056/NEJM1983051930 82002

Riordan, J. R., Rommens, J. M., Kerem, B., Alon, N., Rozmahel, R., Grzelczak, Z., et al. (1989). Identification of the cystic fibrosis gene: cloning and characterization of complementary DNA. Science 245, 1066-1073. doi: $10.1126 /$ science. 2475911

Russell, J. M. (2000). Sodium-potassium-chloride cotransport. Physiol. Rev. 80, 211-276. doi: 10.1152/physrev.2000.80.1.211

Schreiber, R., Faria, D., Skryabin, B. V., Wanitchakool, P., Rock, J. R., and Kunzelmann, K. (2015). Anoctamins support calcium-dependent chloride secretion by facilitating calcium signaling in adult mouse intestine. Pflugers Arch. 467, 1203-1213. doi: 10.1007/s00424-014-1559-2

Sen, M., and Gleason, E. (2006). Immunolocalization of metabotropic glutamate receptors 1 and 5 in the synaptic layers of the chicken 
retina. Vis. Neurosci. 23, 221-231. doi: 10.1017/S095252380 6232073

Sen, M., McMains, E., and Gleason, E. (2007). Local influence of mitochondrial calcium transport in retinal amacrine cells. Vis. Neurosci. 24, 663-678. doi: 10.1017/S0952523807070551

Siraj, A., Chantsalnyam, T., Tayara, H., and Chong, K. T. (2021). Recsno: prediction of protein s-nitrosylation sites using a recurrent neural network. IEEE Access 9, 6674-6682. doi: 10.1109/ACCESS.2021.3049142

Sosa, R., and Gleason, E. (2004). Activation of mGlu modulates Ca2+ currents in retinal amacrine cells from the chick. Vis. Neurosci. 21, 807-816. doi: 10.1017/S0952523804216017

Sosa, R., Hoffpauir, B., Rankin, M. L., Bruch, R. C., and Gleason, E. L. (2002). Metabotropic glutamate receptor 5 and calcium signaling in retinal amacrine cells. J. Neurochem. 81, 973-983. doi: 10.1046/j.1471-4159.2002. 00883.x

Tekmen-Clark, M., and Gleason, E. (2013). Nitric oxide production and the expression of two nitric oxide synthases in the avian retina. Vis. Neurosci. 30, 91-103. doi: 10.1017/S0952523813000126

Tekmen, M., and Gleason, E. (2010). Multiple Ca2+-dependent mechanisms regulate L-type Ca2+ current in retinal amacrine cells. J. Neurophysiol. 104, 1849-1866. doi: 10.1152/jn.00031.2010

Tsui, L. C. (1992). The spectrum of cystic fibrosis mutations. Trends Genet. 8, 392-398. doi: 10.1016/0168-9525(92)90301-j

Veruki, M. L., and Wässle, H. (1996). Immunohistochemical localization of dopamine D1 receptors in rat retina. Eur. J. Neurosci. 8, 2286-2297. doi: 10.1111/j.1460-9568.1996.tb01192.x

Veruki, M. L., and Yeh, H. H. (1994). Vasoactive intestinal polypeptide modulates GABAA receptor function through activation of cyclic AMP. Vis. Neurosci. 11, 899-908. doi: 10.1017/s0952523800003850

Villacres, E. C., Wu, Z., Hua, W., Nielsen, M. D., Watters, J. J., Yan, C., et al. (1995). Developmentally expressed Ca2+-sensitive adenylyl cyclase activity is disrupted in the brains of type I adenylyl cyclase mutant mice. J. Biol. Chem. 270, 14352-14357. doi: 10.1074/jbc.270.24.14352

Warrier, A., Borges, S., Dalcino, D., Walters, C., and Wilson, M. (2005). Calcium from internal stores triggers GABA release from retinal amacrine cells. J. Neurophysiol. 94, 4196-4208. doi: 10.1152/jn.00604.2005

Watt, C. B., and Florack, V. J. (1994). A triple-label analysis demonstrating that enkephalin-, somatostatin-and neurotensin-like immunoreactivities are expressed by a single population of amacrine cells in the chicken retina. Brain Res. 634, 310-316. doi: 10.1016/0006-8993(94)91935-6

Wexler, E. M., Stanton, P. K., and Nawy, S. (1998). Nitric oxide depresses GABAA receptor function via coactivation of cGMP-dependent kinase and phosphodiesterase. J. Neurosci. 18, 2342-2349. doi: 10.1523/JNEUROSCI.18 07-02342.1998

Widdicombe, J. H., Welsh, M. J., and Finkbeiner, W. E. (1985). Cystic fibrosis decreases the apical membrane chloride permeability of monolayers cultured from cells of tracheal epithelium. Proc. Natl. Acad. Sci. U S A 82, 6167-6171. doi: 10.1073/pnas.82.18.6167

Wilson, H. L., and Galione, A. (1998). Differential regulation of nicotinic acid-adenine dinucleotide phosphate and cADP-ribose production by cAMP and cGMP. Biochem. J. 331, 837-843. doi: 10.1042/bj33 10837

Wong, M., and Moss, R. L. (1992). Long-term and short-term electrophysiological effects of estrogen on the synaptic properties of hippocampal CA1 neurons. J. Neurosci. 12, 3217-3225. doi: 10.1523/JNEUROSCI.12-08-03217. 1992

Xia, Z. G., Refsdal, C. D., Merchant, K. M., Dorsa, D. M., and Storm, D. R. (1991). Distribution of mRNA for the calmodulin-sensitive adenylate cyclase in rat brain: expression in areas associated with learning and memory. Neuron 6, 431-443. doi: 10.1016/0896-6273(91) 90251-t

Yang, D. S., Boelen, M. K., and Morgan, I. G. (1997). Development of the enkephalin-, neurotensin-and somatostatin-like (ENSLI) amacrine cells in the chicken retina. Brain Res. Dev. Brain Res. 101, 57-65. doi: 10.1016/s01653806(97)00034-5

Conflict of Interest: The authors declare that the research was conducted in the absence of any commercial or financial relationships that could be construed as a potential conflict of interest.

Publishers Note: All claims expressed in this article are solely those of the authors and do not necessarily represent those of their affiliated organizations, or those of the publisher, the editors and the reviewers. Any product that may be evaluated in this article, or claim that may be made by its manufacturer, is not guaranteed or endorsed by the publisher.

Copyright (c) 2021 Zhong and Gleason. This is an open-access article distributed under the terms of the Creative Commons Attribution License (CC BY). The use, distribution or reproduction in other forums is permitted, provided the original author(s) and the copyright owner(s) are credited and that the original publication in this journal is cited, in accordance with accepted academic practice. No use, distribution or reproduction is permitted which does not comply with these terms. 